\title{
Caracterização dos graus de fragilidades em estados geoecológicos da Unidade de Gerenciamento de Recursos Hídricos do Pontal do Paranapanema (SP, Brasil)
}

\author{
Lucas Prado $\mathrm{OSCO}^{1}$, Marcos Norberto BOIN ${ }^{2}$, Munir Jorge FELÍCIO ${ }^{1}$ \& Ana Paula Marques \\ RAMOS $^{1}$
}

1 Programa de Pós-Graduação em Meio Ambiente e Desenvolvimento Regional, Universidade do Oeste Paulista. Rodovia Raposo Tavares, km 572, Bairro do Limoeiro, Campus II, CEP 19.067-175, Presidente Prudente, SP, Brasil (pradoosco@gmail. com,munir@unoeste.br, anaramos@unoeste.br).

2 Departamento de Geografia, Universidade Federal da Grande Dourados, Rodovia Dourados, Itahum, km 12, Cidade Universitária, C.P. 533, CEP 78804-970, Dourados, MS, Brasil (boinmar@hotmail.com).

Recebido em 12/2015. Aceito para publicação em 07/2017.

Versão online publicada em 21/10/2017 (www.pesquisasemgeociencias.ufrgs.br)

\begin{abstract}
Resumo - O Oeste Paulista, a segunda região mais degradada do Estado de São Paulo, tem na Unidade de Gerenciamento de Recursos Hídricos - UGRHI 22 / Pontal do Paranapanema a maior representação dos danos ao meio ambiente ocorridos nos últimos anos, nesta porção do estado. 0 presente trabalho tem por objetivo caracterizar as unidades ambientais, potencialidades e fragilidades físicas da bacia hidrográfica que compõe a UGRHI 22 por meio da análise integrada e sistêmica dos seus componentes naturais. Nesse sentido, o estudo em questão traz como embasamento teórico e conceitual a teoria da Geoecologia da Paisagem, a qual estabelece que as relações e inter-relações entre os componentes do meio físico possibilitam a reflexão e a compreensão de sua dinâmica. Assim, para a concretização dos objetivos do trabalho, inicialmente, realizou-se o levantamento dos componentes naturais da região, tais como a Geologia, Pedologia, Geomorfologia, dentre outros, o que resultou na elaboração de mapas temáticos que possibilitaram a identificação das características dos elementos da paisagem. Aos componentes atribuiu-se peso de um a cinco, no qual o mais baixo corresponde a uma paisagem estabilizada - e o mais alto a uma paisagem degradada -, tendo vista a identificação da fragilidade segundo suas características físicas Em seguida, a partir da sobreposição dos mapas produzidos a partir desses pesos, calcularam-se suas médias aritméticas. Os resultados apresentam uma definição dos graus atribuídos a cada uma das feições e uma apresentação de um mapa síntese do estado geoecológico, que contribui para o planejamento das atividades antrópicas da UGHR - 22.
\end{abstract}

Palavras-chave: mapa temático, paisagem natural, ambiente físico, geoprocessamento.

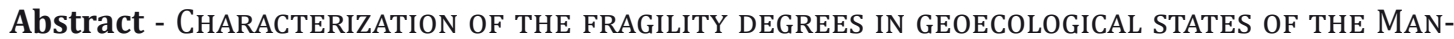
agement Unit of Water Resources of the Pontal do Paranapanema (SP, Brazil). The Oeste Paulista, the second most degraded region in the State of São Paulo, has, in the Water Resources Management Unit - UGRHI 22 / Pontal do Paranapanema, the largest representation of the environmental damage that occurred in recent years in this portion of the state. The present paper aims to characterize the environmental units, potentialities and physical fragilities, throughout the integrated and systematic analysis of the natural components of the hydrographic basin that composes UGRHI 22. Therefore, the study in question brings as its theoretical and conceptual basis the Landscape Geoecology theory, which establishes that the relationships and interrelations between the components of the physical environment make possible to reflex and understand its dynamics. Thus, in order to achieve the objectives of this work, we initially conduct a survey of the regional natural components, such as Geology, Pedology, Geomorphology, and others, which resulted in the elaboration of thematic maps that enabled the identification of the characteristics of the elements of the landscape. We assigned weights from one to five for the landscape's components, in which the lowest corresponds to a stabilized landscape - and the highest to a degraded landscape -, in order to identify the fragility according to its physical characteristics. Then, from the overlapping of the maps produced from these weights, their arithmetic averages were calculated. The results display a definition of the degrees attributed to each of the features and an arrangement of a synthesis map of the geoecological state, which contributes to the planning of UGHR-22's anthropogenic activities. Keywords: thematic map, natural landscape, physical environment, geoprocessing. 


\section{Introdução}

Para Zonneveld (1989), a gênese do estudo geoecológico é antiga, pois remonta aos trabalhos do explorador e geógrafo alemão Alexander von Humboldt (1769-1859), que durante suas diversas expedições naturalistas ao redor do planeta, desenvolveu os conceitos do meio ambiente geográfico, relacionando-os às características da fauna e da flora regionais, à latitude, à tipologia do relevo e às condições climáticas existentes. Contudo, além de Humboldt, Melo (2012) apontou para as contribuições de Vasily Vasili'evich Dokuchaev (18461903), que firmou bases para a Geografia Física e para a Ecologia Biológica, e estabeleceu uma visão voltada para a análise das interações entre a natureza e a sociedade, tendo como base os estudos sobre gênese de solos. Destaca-se, ainda, como um percursor da Ciência Geoecológica, Carl Troll, que em 1932, ao abordar temáticas envolvendo a Ecologia da Paisagem, forneceu subsídios para formar a base da Geoecologia da Paisagem (Abreu, 1983).

O contexto metodológico da Geoecologia consiste na interface entre a Geografia Física, a Geografia Humana, a Biogeografia, a Ecologia e a Cartografia (Silva, 2012). A Geoecologia contribui diretamente para o processo analítico das características da paisagem, proporcionando a elaboração do diagnóstico geoecológico. Rodriguez et al. (2013) afirmaram que a Geoecologia, apesar do diversificado acervo teórico-metodológico, está inserida, sobretudo, na Geomorfologia e na Geografia Física, pois faz uso de métodos e técnicas de ambas as ciências, como, por exemplo, a interpretação das bases naturais de um determinado território, oferecendo subsídios às análises e diagnósticos em diferentes escalas de dimensão espacial. Nesse sentido, a Geoecologia pode ser definida como um ramo das Ciências Naturais, pertencente às Ciências da Terra, e concentrada sobre as observações sistêmicas do meio físico, relacionando-as com o incremento dos impactos ambientais provocados por ações humanas (AGG, 2005).

Conforme Rodriguez et al. (2013), as unidades geoecológicas (ou unidades geoambientais) podem ser entendidas como a individualização da paisagem por meio de unidades regionais ou locais. A regionalização consiste em uma parte fundamental da análise paisagística regional, formando a base de propriedades espaço-temporais dos complexos territoriais. Tais complexos resultaram no conceito teórico básico para a definição do Geossistema pensado por Sotchava (1977), que propõe o estudo integrado da dinâmica do meio natural a partir da análise e síntese de seus componentes. A paisagem, em nível regional, é tida como um geossistema de estrutura complexa, formada por elementos interiores heterogêneos e construídos por associação entre as unidades locais e regionais

Deve-se acrescentar que pesquisadores defenderam ideias diferentes a respeito da avaliação dos processos naturais e do grau de interferência humana na natureza (Crepani et al., 2001; Amaral \& Ross, 2009, e; Rodriguez et al., 2013). Entretanto, permanece inegável a influência de Tricart (1977), que dividiu os meios naturais em três diferentes categorias morfodinâmicas: meio estável, referindo-se à evolução mais lenta do relevo, com prevalência da pedogênese; meio integrade (ou transição), onde ocorre o equilíbrio entre a pedogênese e a morfogênese, e; meio fortemente instável, que é caracterizado pelo domínio dos processos morfogenéticos sobre a pedogênese.

Amaral \& Ross (2009), apoiando-se em Tricart (1977), realizaram uma adaptação metodológica, inserindo no contexto de análise a intervenção humana, de modo a subsidiarem bases para análises das fragilidades desses meios físicos. Drew (1986), por sua vez, reforçou que a intensificação dessas transformações ambientais se encontra extremamente dependente do esforço antrópico realizado num determinado sistema, assim como da condição de resiliência do próprio meio natural. Essas alterações dão sequência a um processo de degradação que resulta em sérias consequências para o meio natural.

Rodriguez et al. (2013) asseguraram que as mudanças no funcionamento e nos mecanismos das relações de autorregulação do próprio meio acabam por conduzi-lo aos processos degradativos, dando margem ao desequilibro de sua dinâmica funcional. Explicaram que a degradação ambiental (ou degradação geoecológica) é definida como a perda dos atributos e propriedades sistêmicas, sendo estas consequências dos processos naturais ou produto direto das atividades antrópicas. Por outro lado, quando um ambiente remanesce inalterado ou em condições naturalmente estabilizadas, o mesmo encontra-se em estado homeostático. Os autores supracitados apontaram como exemplo de processos naturais de degradação a: erosão, perda de biodiversidade, degradação do solo, salinização, redução do nível da água subterrânea, laterização, inundação e outros. E como processos antrópicos, distinguem a: alteração dos recursos hídricos, contaminação do solo, atmosfera e água, movimentação de solos, remoção de vegetação, dentre outras.

Diante das informações apontadas, o presente 
trabalho procura definir e sintetizar as características do meio natural da UGRHI-22, determinando as suas potencialidades e fragilidades e reunindo os componentes naturais dessa paisagem em um mapa temático que contém o estado geoecológico.

\section{2 Área, materiais e métodos}

\subsection{Localização da área de estudo}

A 22 2 anidade de Gerenciamento de Recursos Hídricos do Pontal do Paranapanema (UGRHI-22) ocupa a região ao extremo oeste do estado de São Paulo, em área de encontro entre os estados do Mato Grosso do Sul e do Paraná, onde seus afluentes desembocam nos rios Paraná e Paranapanema. Esta região está localizada entre as coor-

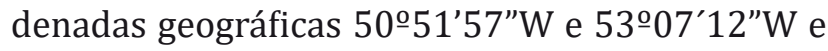
$21^{\circ} 56^{\prime} 58^{\prime \prime}$ e $22^{\circ} 40^{\prime} 28^{\prime \prime}$, abrangendo uma extensão territorial total de aproximadamente 11.838 $\mathrm{km}^{2}$ (CPTI, 1999). A figura 1 ilustra a área de estudo, destacando os municípios, espaços urbanos, estradas e vicinais inseridos na região delimitada. A bacia hidrográfica possui como principal polo econômico o município de Presidente Prudente, abrangendo em sua extensão territorial 26 municípios.

Geologicamente, conforme a clássica divisão litoestratigráfica de Soares et al. (1980), a UGRHI-22 abrange em seu território a formação Serra Geral (grupo São Bento) e as formações Caiuá, Santo Anastácio e Adamantina (grupo Bauru). Estas unidades caracterizam-se, respectivamente, como rochas ígneas e sedimentares, originadas no Mesozoico e recobertas por depósitos sedimentares do Cenozoico. Almeida et al. (1980), por sua vez, propuseram a subdivisão da Formação Adamantina, separando-a em unidades de mapeamento $\left(\mathrm{Ka}_{\mathrm{I}}, \mathrm{Ka}_{\mathrm{II}}, \mathrm{Ka}_{\mathrm{III}}, \mathrm{Ka}_{\mathrm{IV}}\right.$ e $\mathrm{Ka}$ ). Posteriormente, os trabalhos de Almeida et al. (1981) e CPTI (1999), voltados para a região do Pontal do
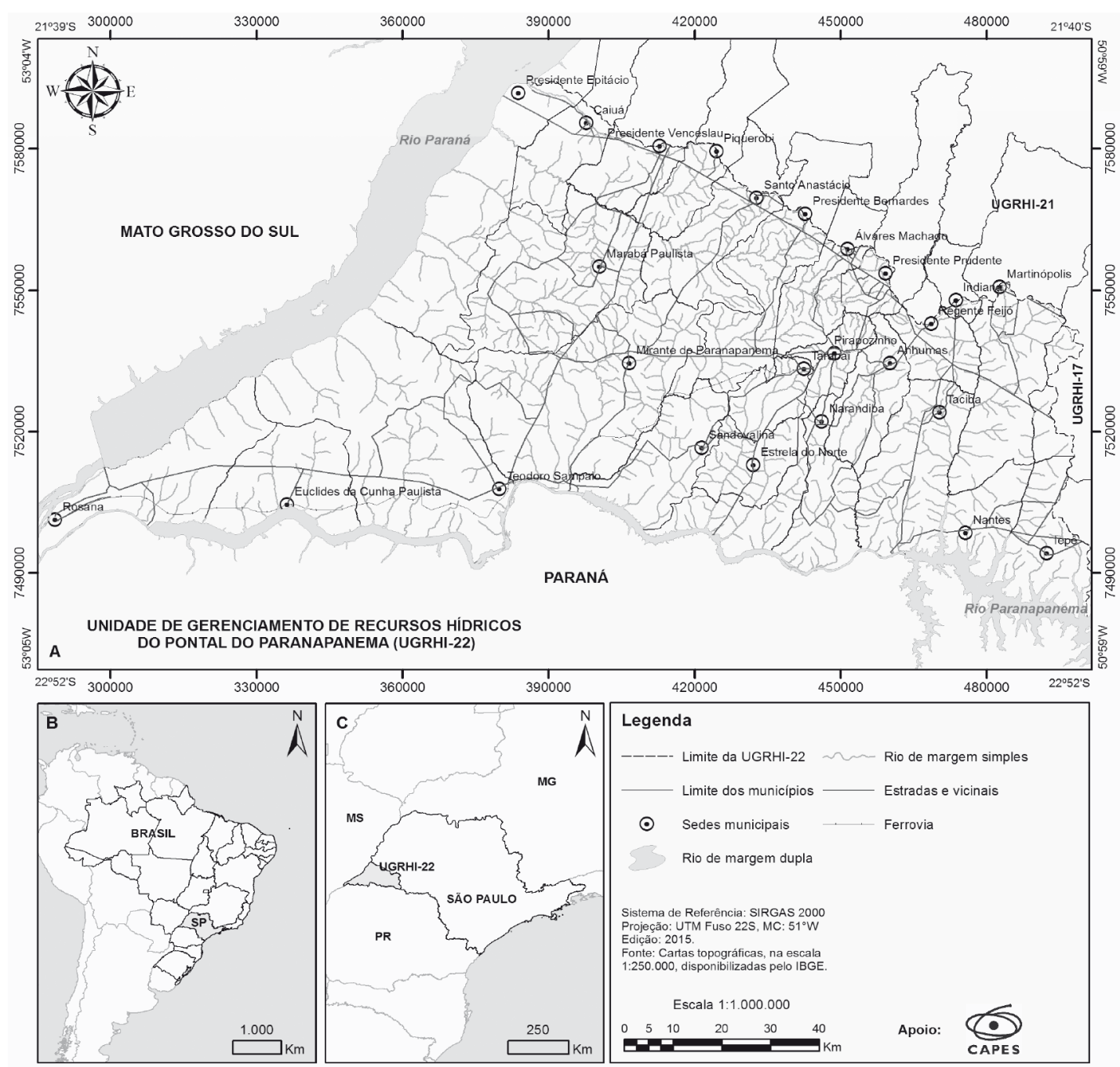

Figura 1. Mapa de localização. A) Área de estudo e a divisão municipal da região do Pontal do Paranapanema (UGRHI-22); B) Localização do estado de São Paulo; C) Localização da UGRHI-22 no Estado de São Paulo (dados disponibilizadas pelo IBGE, 2015). Figure 1. Location Map. A) Study area and the municipal division of the Pontal do Paranapanema region (UGRHI-22); B) Location of the state of São Paulo; C) Location of the UGRHI-22 in the state of São Paulo (data available from IBGE, 2015). 
Paranapanema, demonstraram que somente as unidades $\mathrm{Ka}_{\mathrm{I}}, \mathrm{Ka}_{\mathrm{IV}}$ e $\mathrm{Ka}_{\mathrm{V}}$ encontravam-se aflorantes na área desta região.

Em relação ao quadro estrutural, Paula e Silva et al. (2003) mencionaram uma depressão localizada ao sul do município de Presidente Bernardes, onde a Formação Caiuá encontra-se em maior espessura. Stein (1999) atribuiu a definição Planalto das Lagoas para a área, em razão do seu relevo diferenciado, relacionando-a com estruturas tectônicas que cortam a bacia, além de relatar a baixa densidade de drenagem e a presença de lagoas ao longo de sua extensão. A discrepância dessa área ao sul de Presidente Bernardes pode ser novamente notada no trabalho de Santoro \& Massoli (1985), no qual os autores evidenciaram que, neste ponto, a superfície basáltica comporta-se de maneira sinclinal, cujo eixo do mergulho ocorre na direção nordeste-sudoeste, iniciando-se próximo à cidade de Mariápolis, rebaixando-se no município de Presidente Bernardes e elevando-se, novamente, no município de Marabá Paulista.

Santos et al. (2011), por sua vez, em análise à UGRHI-22, demonstraram que áreas com solos mais espessos correspondem a remanescentes de pediplanos, e indicaram como exemplos o então Planalto das Lagoas, algumas margens dos rios Paraná e Paranapanema e as coberturas de blocos subsidentes, com limites retilíneos controlados por traços de feições lineares. Além disso, constataram um elevado padrão de feições de drenagens no setor oriental da bacia, indicando um relevo altamente dissecado e de solo pouco espesso. Esta área, ao setor oriental, corresponde aos altos estruturais, discutidos por Landim et al. (1984) e Nunes (2002) em estudos passados.

Nas localidades com relevos mais dissecados da UGRHI-22, ocorre a predominância de Argissolos Vermelho e Vermelho-Amarelo, enquanto sobre os locais de relevos mais aplainados encontram-se os Latossolos Vermelhos (EMBRAPA, 1999). No que se refere aos processos erosivos, o Argissolo, em razão da elevada declividade de alguns setores, somado à intensidade do uso, à degradação de seus horizontes e à compactação das camadas sub-superficiais, possui maior suscetibilidade à erosão. Já sobre as áreas de maior dissecação do relevo, com índices de declividade superiores a $15 \%$, encontram-se com maior frequência os $\mathrm{Ne}$ ossolos Litólicos (Oliveira et al., 2015), enquanto nas regiões ao sudoeste da UGRHI-22 são observadas predominâncias de Nitossolos Vermelhos, associados à formação Serra Geral. Outros exemplos de solos encontrados são os do tipo gley (ou solos hidromórficos em geral), comuns em regiões pla- nas, próximas aos corpos d'água e sujeitos a menores riscos de erosão.

No contexto geomorfológico regional, a UGRHI-22 encontra-se inserida na província geomorfológica do Planalto Ocidental Paulista. As características do modelado regional adequam-se às classificações de Ross \& Moroz (1997), distribuindo-se em relevos de degradação (colinas amplas e baixas) e relevos de agradação (planícies e terraços aluviais), compondo o quadro morfológico regional. As colinas amplas estão sobre setores de significativa densidade de drenagem, com maiores índices de dissecação e menor amplitude e distância entre os seus interflúvios, em comparação às colinas baixas. Essas colinas (amplas) normalmente revelam um relevo ondulado ou fortemente ondulado, enquanto as colinas baixas são caracterizadas pelo seu baixo índice de dissecação, com menores classes de declividade, em relevo plano suave a ondulado (Ross \& Moroz, 1996). As planícies situam-se em superfícies planas, próximas aos cursos d'água, e sujeitas periodicamente às inundações. E os terraços possuem leve inclinação no sentido das planícies, alçados a poucos metros acima da várzea, e caracterizados como setores não inundáveis (IPT, 1981a).

Em relação à cobertura vegetal nativa encontrada, a UGRHI-22 apresenta atualmente uma parcela mínima, tendo a reserva do Morro do Diabo (e de outros fragmentos menores) como um dos últimos refúgios da Mata Atlântica do Interior (Floresta Estacional Semidecidual). Esta vegetação distingue-se em função da perda parcial de folhas (de 20\% e 50\%) durante os períodos de seca ou de inverno bastante rígidos, retomando a folhagem nas épocas de chuvas da primavera e do verão (IBGE, 2012). O Cerrado, por sua vez, restringe-se a áreas mais específicas, sobre porções de solos mais espessos, uma vez que suas raízes, de maior comprimento, permitem que as plantas atinjam as zonas mais distantes do solo à procura de água, e encontra-se ao leste e ao centro da UGRHI-22.

Com relação aos condicionantes climáticos da UGRHI-22, Boin (2000) apontou que as passagens de frentes frias e correntes do Sul, associadas à massa Polar Atlântica, encontram-se intimamente ligadas à distribuição de chuvas por todo o oeste paulista. Essas correntes de ar percorrem por sobre os vales no estado do Paraná, conduzindo as massas de ar frias para a região. Ao norte, as massas intertropicais, sobretudo a Tropical Atlântica, possuem comportamento semelhante, deslocando-se com maior frequência sobre o norte do estado de São Paulo. Portanto, os mecanismos frontológicos, criados pela participação da massa 
Polar Atlântica, confrontam-se com a massa Tropical Atlântica sobre a faixa zonal (Boin, 2000), promovendo a precipitação das chuvas neste setor e, consequentemente, seu clima subtropical.

\subsection{Materiais e métodos}

Realizou, primeiramente, o levantamento e a preparação dos dados cartográficos necessários à elaboração do diagnóstico ambiental da UGRHI-22. Nesta etapa da produção cartográfica, levaram-se em consideração os componentes necessários à elaboração do diagnóstico geoecológico. Para tanto, a unificação dos parâmetros naturais, por meio dos mapas temáticos do relevo, rocha, solo, erodibilidade, vegetação e clima, serviram de base para a caracterização dos condicionantes físicos da paisagem. Cabe ressaltar que trabalhos de campo foram realizados para validar os mapas temáticos regionais produzidos. As pesquisas in loco corroboraram o diagnóstico proposto.

A produção cartográfica foi desenvolvida utilizando o software da empresa ESRI, o ArcGIS 10.3, que consistiu na compilação dos mapas elaborados pela CPTI (1999). A base cartográfica, na escala 1:250.000, disponibilizada pela CPTI (1999), foi atualizada com imagens de satélite LANDSAT 8 Sensor OLI e TIRS dos meses de setembro e outubro de 2014, com dados do radar SRTM (Shuttle Radar Topography Mission), divulgadas pela USGS (United States Geological Survey) no ano de 2014 e por ortofotografias cedidas pela EMPLASA (Empresa Paulista de Planejamento Metropolitano, 2011), na escala 1:25.000, e GSD (Ground Simple Distance) de 1 (um) m de resolução.

Os dados foram padronizados para a escala 1:250.000 e organizados em um banco de dados em ambiente SIG (Sistema de Informações Geográficas) no ArcGIS. Foram utilizados dados vetoriais contendo a distribuição de solos, as formas do relevo, a distribuição das rochas, as unidades climáticas, as áreas susceptíveis à erosão e a cobertura vegetal na área em estudo. A partir desse material, designou-se atributos referentes aos graus de fragilidades para cada um dos componentes dos subsistemas naturais. Os valores utilizados nos atributos basearam-se em conceitos e métodos anteriormente elaborados por autores como Crepani et al. (2001), Amaral \& Ross (2009), Rodriguez et al. (2013), Oliveira (2015), dentre outros. Convém destacar que a maior influência na produção do mapa síntese advém dos princípios defendidos por Tricart (1977), bem como do arcabouço teórico dos princípios geoecológicos. Designaram-se, portanto, os graus de fragilidade segundo uma va- riação de 1 a 5, em que o valor 1 corresponde a um menor grau de fragilidade e o valor 5 corresponde ao valor máximo. Os valores foram determinados a partir das características intrínsecas de cada um dos componentes naturais. O levantamento bibliográfico, adjunto à experiência de especialistas e do reconhecimento em campo de áreas variadas da região, proporcionaram melhor definir esses valores.

Posteriormente, os dados foram convertidos para o formato raster, nos quais aplicou a álgebra de mapas para realizar a soma e eventual média aritmética dos valores definidos, o que permitiu obter um mapa síntese contendo o estado geoecológico da UGRHI-22. 0 produto do cruzamento gerou cinco classes de estado geoecológico que foram denominadas como: homeostática, moderado-homeostática, intermediária, moderado-fragilizada e fragilizada. A divisão dos valores obtidos entre essas classes foi realizada a partir do desvio padrão da média aritmética dos graus aplicados.

\section{Resultados}

\subsection{Graus de fragilidades}

O mapa geológico da UGRHI-22 apresenta os afloramentos das formações Serra Geral, Caiuá, Santo Anastácio e Adamantina $\left(\mathrm{Ka}_{\mathrm{I}}, \mathrm{Ka}_{\mathrm{IV}}\right.$ e $\left.\mathrm{Ka}_{\mathrm{v}}\right)$. Para tanto, os critérios empregados embasaram-se em componentes específicos dessa Geologia, como a composição mineralógica e granulométrica que determina a coesão das rochas, a resistência aos processos erosivos e a organização hidrogeológica. Essas características permitiram distribuir melhor os graus de fragilidade dos aspectos Geológicos na região (Quadro 1).

Os graus de fragilidade aplicados nas formas do relevo adquiriram o caráter de suas propriedades associadas aos processos de acúmulo e de remoção (Quadro 2), pois essas formas revelam particularidades significativas. As características do modelado regional adequam-se às classificações de Ross \& Moroz (1997), distribuindo-se em relevos de degradação (colinas amplas e baixas) e relevos de agradação (planícies e terraços aluviais), compondo o quadro morfológico regional.

No que se refere aos tipos de solos da UGRHI-22, os mesmos distribuem-se, conforme a classificação de EMBRAPA (1999), em Latossolos Vermelho (LV29, LV39, LV45, LV49, LV54, LV63), Argissolos Vermelho (PV4) e Vermelho-Amarelo (PVA1, PVA2, PVA4, PVA5, PVA10), Nitossolo Vermelho (NV1), Neossolos Litólico (R, R9) e Gleisso- 
lo Háplico (GX8). 0 presente trabalho optou por levar em consideração critérios como o ambiente de ocorrência, composição granulométrica e mineralógica, e a capacidade de infiltração ou retenção da água superficial por esses solos, tendo como intenção designar os atributos de fragilidade a cada classificação de solos (Quadro 3).

Além da distribuição regional dos solos, levou-se em consideração as condições de susceti- bilidade aos processos erosivos (CPTI, 1999). Tal condição reflete o balanço pedogênese/morfogênese, no qual as propriedades dos solos atrelam-se a fatores condicionados pelos demais componentes da paisagem. Para tanto, adotou-se essas classes como componente fundamental no cruzamento das informações relativas ao grau de fragilidade (Quadro 4).

Quadro 1. Subsistema litoestratigráfico e respectivos graus de fragilidade (descrições modificadas de IPT, 1981b, Soares et al., 1980 e Almeida et al., 1981; graus determinados pelos autores).

Chart 1. Lithostratigraphic subsystem and respective degrees of frailty (modified descriptions of IPT, 1981b, Soares et al., 1980 and Almeida et al., 1981; degrees determined by the authors).

\begin{tabular}{|c|c|c|}
\hline Cenozoico (Quaternário) & Descrição & Grau \\
\hline Depósitos aluvionares (Qa) & $\begin{array}{l}\text { Aluviões em geral, incluindo areias de granulação variável, argilas e, } \\
\text { subordinadamente, cascalheiras, formando depósitos de calha e/ou } \\
\text { terraços. }\end{array}$ & 5 \\
\hline Grupo Bauru (Cretáceo) & Descrição & Grau \\
\hline Adamantina $\left(\mathrm{Ka}_{\mathrm{v}}\right)$ & $\begin{array}{l}\text { Arenitos finos a muito finos, quartzosos, com frequentes intercalações de } \\
\text { argilitos e siltitos, formando bancos pouco espessos. Localizadamente, } \\
\text { arenitos com pelotas de argila. Frequente presença de cimentação } \\
\text { carbonática e, mais raramente, de nódulos. }\end{array}$ & 4 \\
\hline Adamantina $\left(\mathrm{Ka}_{\mathrm{IV}}\right)$ & $\begin{array}{l}\text { Arenitos finos a muito finos, quartzosos, com frequentes intercalações de } \\
\text { argilitos e siltitos, formando bancos espessos. Localizadamente, arenitos } \\
\text { com pelotas de argila. Frequente presença de cimentação carbonática e, } \\
\text { mais raramente, de nódulos. }\end{array}$ & 4 \\
\hline Adamantina $\left(\mathrm{Ka}_{\mathrm{I}}\right)$ & $\begin{array}{l}\text { Arenitos finos a muito finos, silititos arenosos, arenitos argilosos, } \\
\text { subordinadamente arenitos com granulação média, quartzosos, } \\
\text { localmente arcoseanos. }\end{array}$ & 3 \\
\hline Santo Anastácio (Ksa) & $\begin{array}{l}\text { Arenitos finos a médios, mal selecionados, subordinadamente, arcoseanos, } \\
\text { geralmente maciços, localmente com cimento e nódulos carbonáticos. }\end{array}$ & 4 \\
\hline Caiuá (Kc) & $\begin{array}{l}\text { Arenitos finos e médios, bem arredondados, cores de tonalidade roxa. } \\
\text { Localmente, cimento e nódulo carbonático. }\end{array}$ & 2 \\
\hline $\begin{array}{l}\text { Grupo São Bento } \\
\text { (Jurássico) }\end{array}$ & Descrição & Grau \\
\hline Serra Geral (JKsg) & $\begin{array}{l}\text { Derrames basálticos toleísticos, textura afanítica, com intercalações de } \\
\text { arenitos finos a médios, intertrapeanos. }\end{array}$ & 1 \\
\hline
\end{tabular}

Quadro 2. Subsistema geomorfológico e respectivos graus de fragilidade (descrições modificadas de IPT, 1981a e Ross \& Moroz, 1997; graus determinados pelos autores).

Chart 2. Geomorphological subsystem and respective degrees of frailty (modified descriptions of IPT, 1981a and Ross \& Moroz, 1997; degrees determined by the authors).

\begin{tabular}{|c|l|c|}
\hline Relevo de agradação & Descrição & Grau \\
\hline $\begin{array}{c}\text { Planícies aluviais } \\
\text { (Apf) }\end{array}$ & $\begin{array}{l}\text { Terrenos baixos e mais ou menos planos, junto às margens dos rios, } \\
\text { sujeitos periodicamente a inundações. }\end{array}$ & 5 \\
\hline $\begin{array}{c}\text { Terraços aluviais } \\
\text { (Apf) }\end{array}$ & $\begin{array}{l}\text { Terrenos horizontais ou levemente inclinados, junto às margens dos rios, } \\
\text { alçados de poucos metros em relação às várzeas, não inundáveis. }\end{array}$ & 5 \\
\hline $\begin{array}{c}\text { Relevo de } \\
\text { degradação }\end{array}$ & Descrição & Grau \\
\hline Colinas amplas (Dc) & $\begin{array}{l}\text { Relevo com topos extensos e aplainados, vertentes com perfis retilíneos a } \\
\text { convexos. }\end{array}$ & 3 \\
\hline Colinas baixas (Dt) & Relevo pouco dissecado com feições em topo tabular. & 1 \\
\hline
\end{tabular}


Quadro 3. Subsistema pedológico e respectivos graus de fragilidade (descrições modificadas de EMBRAPA, 1999 e CPTI, 1999 ; graus determinados pelos autores).

Chart 3. Pedological subsystem and respective degrees of frailty (modified descriptions of EMBRAPA, 1999 and CPTI, 1999; degrees determined by the authors).

\begin{tabular}{|c|c|c|}
\hline Latossolo Vermelho & Descrição & Grau \\
\hline LV29 & $\begin{array}{l}\text { Distroférricos e Eutroférricos text. argilosa + LATOSSOLOS VERMELHOS } \\
\text { Distróficos todos A moderado rel. suave ondulado + NITOSSOLOS } \\
\text { VERMELHOS Eutroférricos rel. ondulado + NEOSSOLOS LITÓLICOS } \\
\text { Eutróficos A moderado e Chernozêmico rel. forte ondulado. }\end{array}$ & 1 \\
\hline LV39 & Distróficos A moderado text. argilosa rel. plano e suave ondulado. & 1 \\
\hline LV45 & Distróficos A moderado text. média rel. plano e suave ondulado. & 1 \\
\hline LV49 & $\begin{array}{l}\text { Distróficos + LATOSSOLOS VERMELHO-AMARELOS Distróficos ambos A } \\
\text { moderado text. média rel. suave ondulado. }\end{array}$ & 1 \\
\hline LV54 & $\begin{array}{l}\text { Distróficos text. argilosa e média + LATOSSOLOS VERMELHOS Eutroférricos } \\
\text { e Distroférricostext. argilosa ambos A moderado rel. plano e suave } \\
\text { ondulado. }\end{array}$ & 1 \\
\hline LV63 & $\begin{array}{l}\text { Distróficos text. argilosa rel. plano + ARGISSOLOS VERMELHOS Eutróficos } \\
\text { text. média/argilosa e média rel. suave ondulado ambos A moderado. }\end{array}$ & 1 \\
\hline Argissolo Vermelho & Descrição & Grau \\
\hline PV4 & Distróficos A moderado text. arenosa/média e média rel. suave ondulado. & 3 \\
\hline $\begin{array}{l}\text { Argissolo Vermelho- } \\
\text { Amarelo }\end{array}$ & Descrição & Grau \\
\hline PVA1 & $\begin{array}{l}\text { Eutróficos abrúpticos A moderado text. arenosa/média rel. suave ondulado } \\
\text { e ondulado. }\end{array}$ & 3 \\
\hline PVA2 & $\begin{array}{l}\text { Eutróficos abrúpticos ou não, A moderado text. arenosa/média e média rel. } \\
\text { suave ondulado e ondulado. }\end{array}$ & 3 \\
\hline PVA4 & $\begin{array}{l}\text { Eutrófico abrúptos text. arenosa/média rel. suave ondulado e ondulado + } \\
\text { ARGISSOLOS VERMELHO-AMARELOS Eutróficos abrúpticos text. arenosa/ } \\
\text { média rel. suave ondulado ambos A moderado. }\end{array}$ & 3 \\
\hline PVA5 & $\begin{array}{l}\text { Eutróficos text. arenosa/média rel. ondulado e suave ondulado + ARGISSOLOS } \\
\text { VERMELHO-AMARELOS Eutróficos pouco profundos text. arenosa/argilosa } \\
\text { rel. ondulado ambos abrúpticos A moderado. }\end{array}$ & 3 \\
\hline PVA10 & $\begin{array}{l}\text { Eutróficos + ARGISSOLOS VERMELHOS Distróficos e Eutróficos ambos text. } \\
\text { arenosa/média e média rel. suave ondulado + LATOSSOLOS VERMELHOS } \\
\text { Distróficos text. média rel. plano todos A moderado. }\end{array}$ & 3 \\
\hline Nitossolo Vermelho & Descrição & Grau \\
\hline NV1 & $\begin{array}{l}\text { Eutroférricos + LATOSSOLOS VERMELHOS Eutroférricos ambos A moderado } \\
\text { text. argilosa rel. suave ondulado e ondulado. }\end{array}$ & 2 \\
\hline Neossolo & Descrição & Grau \\
\hline $\mathrm{R}$ & Neossolo Litólico Eutrófico típico. & 5 \\
\hline R9 & $\begin{array}{l}\text { Distróficos A moderado text. média rel. forte ondulado + AFLORAMENTO DE } \\
\text { ROCHAS. }\end{array}$ & 5 \\
\hline Gleissolo Háplico & Descrição & Grau \\
\hline GX8 & $\begin{array}{l}\text { Tb + NEOSSOLOS FLÚVICOS A moderado ambos Eutróficos e Distróficos text. } \\
\text { indiscriminada rel. de várzea. }\end{array}$ & 4 \\
\hline
\end{tabular}


Quadro 4. Suscetibilidade à erosão e respectivos graus de fragilidade (descrições modificadas de CPTI, 1999 e IPT, 1994; graus determinados pelos autores).

Chart 4. Susceptibility to erosion and respective degrees of frailty (modified descriptions of CPTI, 1999 and IPT, 1994; degrees determined by the authors).

\begin{tabular}{|c|l|c|}
\hline $\begin{array}{c}\text { Classe de } \\
\text { erodibilidade }\end{array}$ & Descrição & Grau \\
\hline Muito baixo & $\begin{array}{l}\text { Áreas não suscetíveis ao desenvolvimento de ravinas e boçorocas. Solos GLEY } \\
\text { pouco húmicos a PLANOSSOLOS em relevos de agradação. }\end{array}$ & 1 \\
\hline Baixo & $\begin{array}{l}\text { Áreas pouco suscetíveis ao desenvolvimento de ravinas rasas. LATOSSOLO roxo e } \\
\text { terra estruturada de textura muito argilosa em relevos de colinas amplas. }\end{array}$ & 2 \\
\hline Médio & $\begin{array}{l}\text { Áreas suscetíveis ao desenvolvimento de ravinas e boçorocas. LATOSSOLOS de } \\
\text { textura média e areias quatzosas em relevos de colinas amplas. }\end{array}$ & 3 \\
\hline Alto & $\begin{array}{l}\text { Áreas muito suscetíveis ao desenvolvimento de ravinas e boçorocas. ARGISSOLOS } \\
\text { de textura arenosa e média em relevos de colinas amplas. }\end{array}$ & 4 \\
\hline Muito alto & $\begin{array}{l}\text { Áreas extremamente suscetíveis ao desenvolvimento de ravinas e boçorocas. } \\
\text { ARGISSOLOS de textura arenosa e média em relevos de colinas médias, morrotes e } \\
\text { espigões alongados. Áreas de cabeceiras de drenagem com erosão acelerada. }\end{array}$ & 5 \\
\hline
\end{tabular}

Destacam-se, na UGHRI-22, coberturas nativas de vegetação que se encontram sobre os domínios da Mata Atlântica e em setores específicos do Cerrado. Nos setores florestados, compostos por quaisquer matas nativas (primárias ou secundárias), desde que indiquem um nível de formação densa, designou-se um grau mínimo, enquanto as áreas descampadas, tomadas ou não por atividades de pecuária, agricultura (permanente ou temporária), ou gramíneas e vegetações em estado inicial, receberam o grau máximo (Quadro 5).

Por fim, caracterizaram-se os condicionantes climáticos na UGRHI-22, responsáveis por reger, juntamente com outros aspectos endógenos e exógenos, os demais componentes da paisagem natural. No que se refere às massas de ar atuantes sobre a região, Boin (2000) demonstra que as passagens de frentes frias e correntes do Sul, associadas à massa Polar Atlântica, encontram-se intimamente interligadas à distribuição de chuvas por todo o oeste paulista. Destarte, apesar de ter levantado os aspectos climáticos regionais no presente trabalho, deve-se mencionar que os atributos estabelecidos a cada uma de suas unidades climáticas apresentam valores idênticos, e, portanto, foram desconsiderados.

\subsection{Estados geoecológicos da área de estudo}

Depois de levantadas as informações referidas, atribuídos os pesos, realizada uma sobreposição dos mapas e, posteriormente, calculada a média dos valores, obteve-se o mapa síntese com os estados geoecológico da UGRHI-22. 0 resultado encontra-se apresentado no mapa da figura 2 , que revela características essenciais para a compreen- são dos componentes naturais da bacia hidrográfica estudada. Essas características acabam por agrupar e sintetizar os aspectos da condição natural em que a região se encontra. Além disso, oferecem a opção de se atrelar a condição natural com o modo de uso antrópico atual, levando em consideração as recomendações específicas para cada um de seus setores (Quadro 6). Os valores foram divididos em cinco classes a partir do cálculo do seu desvio padrão. Os estados geoecológicos apresentados referem-se somente aos graus de fragilidade do meio físico, não havendo um cruzamento de mapas com o uso e a ocupação da terra atual.

0 agrupamento dos graus se deu conforme os estados geoecológicos, tendo em visa o desvio-padrão como método de classificação. Os estados receberam a seguinte designação: fragilizado, moderado-fragilizado, intermediário, moderado-homeostático, e homeostático, denominados em conformidade com as etapas dos processos de degradação geoecológica definidas por Rodriguez et al. (2013).

Estado Geoecológico Fragilizado: distribuem-se em setores específicos da região, como os altos estruturais e altos topográficos de Presidente Prudente e de Marabá Paulista, o divisor de águas entre a bacia do Pontal do Paranapanema e a bacia do rio do Peixe, e noutras localidades como ao centro-sul, no município de Estrela do Norte, predominantemente, em porções dos arenitos Adamantina $\left(\mathrm{Ka}_{\mathrm{IV}}\right.$ e $\left.\mathrm{Ka}_{\mathrm{v}}\right)$ e, em certos casos, do arenito Santo Anastácio, onde ocorrem acentuados processos erosivos. Além dos processos erosivos sobre as vertentes, essas unidades não costumam possuir cobertura de vegetação arbórea, contribuindo com o agravamento de suas condições e promovendo 
Quadro 5. Cobertura vegetal e respectivos graus de fragilidade (descrições modificadas de IBGE, 2012; graus determinados pelos autores).

Chart 5. Vegetation cover and respective degrees of frailty (modified descriptions of IBGE, 2012; degrees determined by the authors).

\begin{tabular}{|c|l|c|}
\hline Região de florestas & Descrição & Grau \\
\hline $\begin{array}{c}\text { Floresta Estacional } \\
\text { Semidecidual }\end{array}$ & $\begin{array}{l}\text { Conhecida como Mata Atlântica do Interior, ocupa ambientes desde a zona } \\
\text { úmida costeira ao ambiente semiárido. Apresenta porte em torno de 20 m (no } \\
\text { seu estrato mais alto) e caracteriza-se por sua razoável perda de folhas (cerca } \\
\text { de 50\%) nos períodos mais secos do ano. }\end{array}$ & 1 \\
\hline Cerrado & $\begin{array}{l}\text { Dominância compartilhada das florestas arbórea e herbácea. A arbórea possui } \\
\text { árvores de porte médio ou baixo (de 3 a 10 m), geralmente espaçadas, e copas } \\
\text { amplas, de esgalhamento baixo. A herbácea é praticamente contínua, criando } \\
\text { um tapete entre árvores e arbustos. }\end{array}$ & 1 \\
\hline Região descampada & Descrição & Grau \\
\hline Gramínea & $\begin{array}{l}\text { Áreas expressivas em setores menos aplainados e desmatados, com baixa } \\
\text { proteção ao solo e de uso exclusivo para atividades de pastoreio. }\end{array}$ & 5 \\
\hline Cultura & $\begin{array}{l}\text { Localizadas em diversos setores, caracterizam-se por temporárias ou } \\
\text { permanentes, mecanizadas ou não, tomando espaços outrora compostos por } \\
\text { vegetações nativas. }\end{array}$ & 5 \\
\hline
\end{tabular}
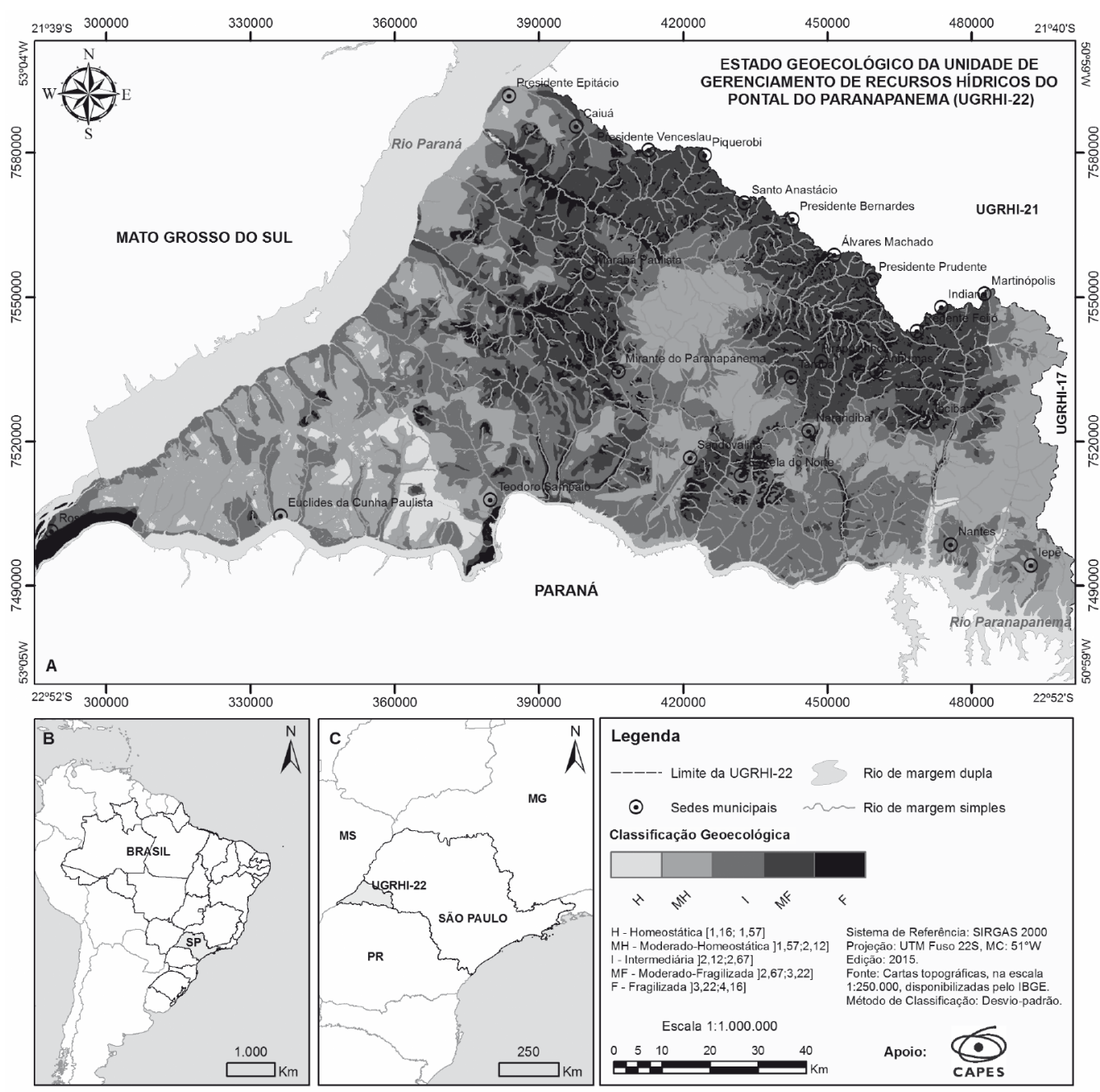

Figura 2. Mapa geoecológico. A) Mapa temático do estado geoecológico do Pontal do Paranapanema (UGRHI-22); B) Localização do estado de São Paulo; C) Localização da UGRHI-22 no estado de São Paulo (limites geográficos disponibilizados pelo IBGE, 2015).

Figure 2. Geoecological map. A) Thematic map of the geological state of Pontal do Paranapanema (UGRHI-22); B) Location of the State of São Paulo; C) Location of the UGRHI-22 in the state of São Paulo (geographical limits available from IBGE, 2015). 
Quadro 6. Estados geoecológicos e suas respectivas descrições. Chart 6. Geoecological states and their respective descriptions.

\begin{tabular}{|c|c|c|c|}
\hline Estado geoecológico & Condições naturais & Uso antrópico atual & Recomendações \\
\hline Fragilizado & $\begin{array}{l}\text { Meio com intensa atuação morfogê- } \\
\text { nica, com processos erosivos acen- } \\
\text { tuados, de topografia acidentada e } \\
\text { elevada declividade. Possui solos } \\
\text { muito rasos, em relevo fortemente } \\
\text { ondulado com altos graus de disse- } \\
\text { cação. Há altíssima densidade de } \\
\text { drenagem, com predominâncias de } \\
\text { lençóis aflorantes em meia encosta } \\
\text { e terraços e planícies aluviais nos } \\
\text { fundos de vale, e de áreas de várze- } \\
\text { as dos cursos d'água, composta por } \\
\text { depósitos cenozoicos. Possui baixa } \\
\text { ou nula vegetação natural. }\end{array}$ & $\begin{array}{l}\text { Predominantemente pas- } \\
\text { tagem, com poucos as- } \\
\text { sentamentos humanos e } \\
\text { agriculturas permanentes } \\
\text { ou temporárias. Caracte- } \\
\text { rizado por uma intensa } \\
\text { ocupação urbana, conten- } \\
\text { do aterros de resíduos só- } \\
\text { lidos, distritos industriais, } \\
\text { estações de tratamento } \\
\text { de efluentes, e apresenta } \\
\text { uma maior ramificação do } \\
\text { sistema viário. }\end{array}$ & $\begin{array}{l}\text { Impróprio à ocupação humana, } \\
\text { à atividades de pastoreio e } \\
\text { agricultura com maquinários } \\
\text { pesados. Deve-se priorizar a } \\
\text { recuperação local, oferecendo } \\
\text { proteção das áreas com corpos } \\
\text { d'água quando houver, e o } \\
\text { reflorestamento e a preservação } \\
\text { da vegetação, além de práticas } \\
\text { de remediação e conservação do } \\
\text { solo. }\end{array}$ \\
\hline Moderado fragilizado & $\begin{array}{l}\text { Meio relativamente instável, com } \\
\text { ocorrência menos intensiva dos } \\
\text { processos erosivos que o meio Fra- } \\
\text { gilizado. Apresenta topografia pou- } \\
\text { co acidentada com menor declivi- } \\
\text { dade, solos relativamente rasos, } \\
\text { relevo colinoso ondulado e bem } \\
\text { dissecado, além de uma elevada } \\
\text { densidade de drenagem com pouca } \\
\text { cobertura de vegetação natural. }\end{array}$ & $\begin{array}{l}\text { Composta por ativida- } \\
\text { des de pastoreio, assen- } \\
\text { tamentos e agriculturas } \\
\text { permanentes ou tempo- } \\
\text { rárias mais diversificadas. } \\
\text { Ocupação urbana com } \\
\text { aterros de resíduos sóli- } \\
\text { dos e estações de trata- } \\
\text { mento de efluentes. }\end{array}$ & $\begin{array}{l}\text { Apto à ocupação humana e agri- } \\
\text { culturas quando não sobre áreas } \\
\text { protegidas, levando em conside- } \\
\text { ração os cuidados a serem toma- } \\
\text { dos. Alguns setores específicos } \\
\text { necessitam de reflorestamento e } \\
\text { práticas de preservação das ma- } \\
\text { tas existentes e da conservação } \\
\text { de solos. }\end{array}$ \\
\hline Intermediário & $\begin{array}{l}\text { Meio em equilíbrio pedogênese/ } \\
\text { morfogênese, de topografia pouco } \\
\text { acidentada e grau de dissecação } \\
\text { mediano. Solos pouco profundos, } \\
\text { em relevo aplainado, de colinas } \\
\text { suave onduladas, com média } \\
\text { densidade de drenagem e a } \\
\text { presença de alguns fragmentos de } \\
\text { vegetação natural. }\end{array}$ & $\begin{array}{l}\text { Pouca pastagem e assen- } \\
\text { tamentos, porém com } \\
\text { uma exacerbada concen- } \\
\text { tração de agriculturas de } \\
\text { cana-de-açúcar e, em al- } \\
\text { gumas porções, de áreas } \\
\text { destinadas à silvicultura. }\end{array}$ & $\begin{array}{l}\text { Apto à ocupação humana, à ati- } \\
\text { vidades de pastoreio e agricul- } \\
\text { turas mecanizadas, quando de } \\
\text { modo controlado. Recomenda-se } \\
\text { o reflorestamento de áreas im- } \\
\text { próprias para outros fins senão à } \\
\text { conservação, como por exemplo } \\
\text { matas existentes e áreas próxi- } \\
\text { mas aos corpos d'água. }\end{array}$ \\
\hline $\begin{array}{c}\text { Moderado } \\
\text { homeostático }\end{array}$ & $\begin{array}{l}\text { Meio relativamente estável, com } \\
\text { maior ocorrência dos processos } \\
\text { pedogenéticos, de topografia } \\
\text { menos acidentada e baixos índices } \\
\text { de dissecação. Caracteriza-se por } \\
\text { seus solos profundos. O relevo } \\
\text { varia de aplainado a plano, de } \\
\text { colinas baixas, e apresenta áreas } \\
\text { com média densidade de drenagem } \\
\text { e com quantidade razoável de } \\
\text { fragmentos de vegetação natural. }\end{array}$ & $\begin{array}{l}\text { Setores dominados por } \\
\text { monoculturas de cana- } \\
\text {-de-açúcar, com baixo ín- } \\
\text { dice de ocupação urbana, } \\
\text { contendo poucos assenta- } \\
\text { mentos. As atividades de } \\
\text { pecuária são praticamen- } \\
\text { te inexistentes. Porém } \\
\text { existem várias extensões } \\
\text { de terras arrendadas ou } \\
\text { pertencentes às usinas } \\
\text { sucroalcooleiras. }\end{array}$ & $\begin{array}{l}\text { Apto à ocupação humana, às } \\
\text { atividades de pastoreio e agri- } \\
\text { culturas mecanizadas, desde } \\
\text { que seja cumprida a proteção } \\
\text { de determinados espaços natu- } \\
\text { rais. Recomenda-se a preserva- } \\
\text { ção das matas existentes e o uso } \\
\text { controlado do solo e dos demais } \\
\text { recursos naturais. }\end{array}$ \\
\hline Homeostático & $\begin{array}{l}\text { Meio estabilizado, com predomi- } \\
\text { nância da pedogênese, de topogra- } \\
\text { fia pouquíssimo acidentada e com } \\
\text { baixo grau de dissecação. Os solos } \\
\text { são muito espessos, em relevo es- } \\
\text { sencialmente plano, de colinas bai- } \\
\text { xas. Caracteriza-se por uma média } \\
\text { à baixa densidade de drenagem, } \\
\text { com quantidades expressivas de } \\
\text { fragmentos de vegetação natural. }\end{array}$ & $\begin{array}{l}\text { Próximas a monoculturas } \\
\text { de cana-de-açúcar, com } \\
\text { poucas ou nulas ocupa- } \\
\text { ções urbanas, atividades } \\
\text { de pecuária e diversidade } \\
\text { de culturas permanentes. }\end{array}$ & $\begin{array}{l}\text { Não recomendado à ocupação } \\
\text { humana. A destinação dessas } \\
\text { áreas deve ser exclusiva à manu- } \\
\text { tenção local por meio da prote- } \\
\text { ção e preservação das matas e da } \\
\text { vida silvestre existentes. O uso } \\
\text { do solo e dos demais recursos } \\
\text { naturais nas proximidades des- } \\
\text { sas áreas deve ocorrer de manei- } \\
\text { ra controlada. }\end{array}$ \\
\hline
\end{tabular}


o assoreamento dos corpos hídricos e o aparecimento de sulcos, ravinas e boçorocas, ocasionando transformações no modelado. As unidades em estado fragilizado também competem às áreas dos depósitos cenozoicos, que se distribuem sobre as várzeas, planícies e terraços dos grandes rios (Fig. 3).

Esse estado caracteriza-se por acentuados processos erosivos, associados a uma topografia mais acidentada, de relevo bem dissecado e com índices de declividade superiores a 15\%. Além disso, são áreas que se concentram sobre solos mais recentes, como o próprio Neossolo Litólico, ou em algumas das áreas predominantemente compostas por Agissolos Vermelho e Vermelho-Amarelos. Os Latossolos Vermelhos são encontrados sobre porções menos expressivas desses setores, normalmente situados nos topos e divisores de água, em vertentes aproximadamente planas, com forma convexa. Atualmente, essas unidades encontram-se intensamente ocupadas, pois coincidem com o desenvolvimento das cidades no entorno dos divisores de água regionais. Salienta-se que essas unidades devem receber a devida recuperação e proteção ambiental, conforme destacado no Quadro 6.

Estado Geoecológico Moderado-Fragilizado: encontra-se geralmente próximo das unidades de estado fragilizado, limitando-se a setores de topografia bem acidentada, com menores índices de declividade em relação à classificação anterior, ainda que situado sobre relevo de colinas amplas de semelhantes graus de dissecação. As unidades geoecológicas moderado-fragilizado concentram significativa quantidade de lençóis suspensos na meia encosta (freático local), assim como planícies e terraços de menor expressão quando comparados àqueles destacados nas unidades fragilizadas. 0 substrato rochoso encontra-se sujeito a processos erosivos, embora com menor intensidade do que na unidade anterior (Fig. 4).

Os solos desse estado dividem-se, predominantemente, entre os Argissolos Vermelho e Vermelho-Amarelos e Nitossolos Vermelhos, que acompanham as colinas amplas por uma vasta parcela da região. Além disso, a quantidade de fragmentos de vegetação nativa é baixa ou nula. Suas áreas encontram-se aptas à ocupação humana somente quando tomados os cuidados necessários, levando-se em consideração todas as características descritas. Atualmente, essas áreas têm sido utilizadas para atividades de pecuária, o que compromete a qualidade dos recursos naturais quando conduzidas de maneira inadequada.

Estado Geoecológico Intermediário: destaca-

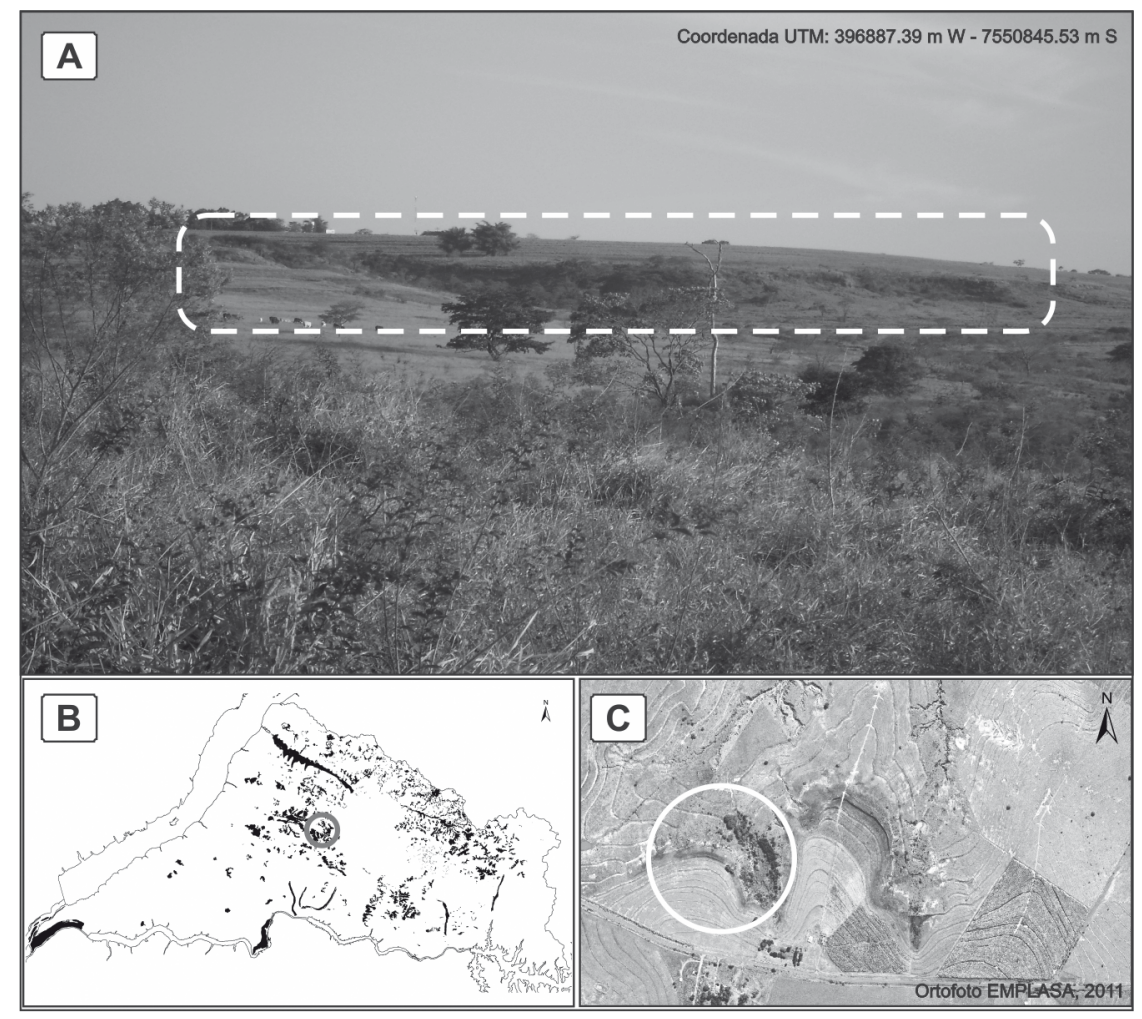

Figura 3. Exemplo de paisagem em estado geoecológico fragilizado no município de Marabá Paulista. A) Foto em campo; B) Localização da área na UGRHI-22; C) Visão aérea do local a partir de fotografia aérea (disponibilizada pela EMPLASA, 2011). Figure 3. Example of a fragile geoecological landscape in the municipality of Marabá Paulista. A) Field photo; B) Location of the area at the UGRHI-22; C) Aerial view of the site from aerial photography (available from EMPLASA, 2011). 
-se pelo equilíbrio entre a pedogênese e a morfogênese, uma vez que os processos erosivos ocorrem de modo controlado, permitindo a formação de solos pouco mais profundos do que aqueles das unidades anteriormente destacadas sobre relevo de colinas amplas, com predomínio de Argissolos Vermelho e Vermelho-Amarelo e de setores com Latossolos Vermelhos. Essas áreas possuem um índice médio de densidade de drenagem, com feições erosivas de menor porte, e, em certas porções, são compostas por coberturas de vegetação arbórea. Tais unidades são adequadas à ocupação humana, atividades de pecuária e até mesmo agriculturas mecanizadas.

Sua ocorrência é comum ao sul da região, em municípios com afloramentos da unidade KaI da Formação Adamantina e com menores índices de declividade, assim como em áreas relativamente próximas a setores mais dissecados, como ao noroeste da região. Deve-se reforçar a necessidade da preservação das matas nativas existentes e de um maior cuidado no entorno dos cursos d'água e lençóis freáticos locais (suspensos em meia encosta), quando houverem (Fig. 5).

Estado Geoecológico Moderado-Homeostático: são unidades em condições mais estáveis, onde existe uma maior atuação da pedogênese sobre a morfogênese. A predominância de colinas baixas, com relevo suave ondulado ou plano, de topografia pouco acidentada e menor grau de dissecação do modelado conferem a essas áreas maior estabilidade. Os solos apresentam maior profundidade, evidenciados por vegetações transitórias entre a Mata Atlântica e o Cerrado, além da presença de pouquíssimos, praticamente nulos, lençóis freáticos suspensos em meia encosta, quando comparada às unidades geoecológicas de estados fragilizado e moderado-fragilizado.

A presença de corpos hídricos superficiais nessas áreas é menor, uma vez que a baixa densidade de drenagem se deve ao domínio dos arenitos Caiuá e Adamantina $\left(\mathrm{Ka}_{\mathrm{I}}\right)$ e a ocorrência de relevos mais aplainados, com maior distância entre os seus interflúvios e menor dissecação. Essas áreas são consideradas adequadas à ocupação humana, desde que se mantenham as devidas precauções quanto a setores específicos, como matas galerias e em áreas de topografia mais acidentada quando existirem. Em razão de seu relevo plano, com solos bem desenvolvidos, muitas dessas áreas encontram-se ocupadas por grandes propriedades, com a cultura da cana-de-açúcar, uma vez que as características físicas descritas facilitam a operação de maquinários pesados (Fig. 6). Na figura 6C é pos-

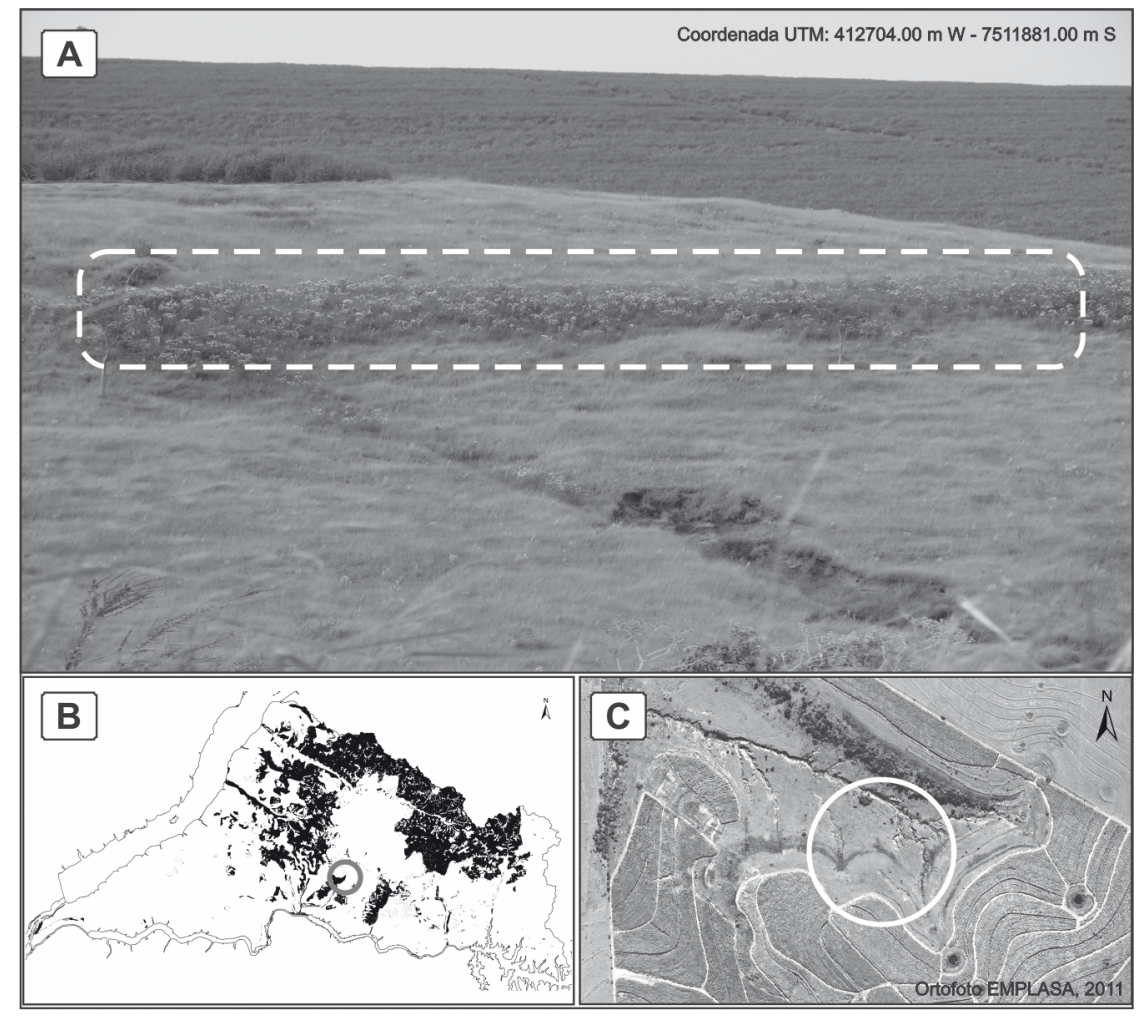

Figura 4. Exemplo de paisagem em estado geoecológico moderado-fragilizado no município de Sandovalina. A) Foto em campo; B) Localização da área na UGRHI-22; C) Visão aérea do local a partir de fotografia aérea (disponibilizada pela EMPLASA, 2011). Figure 4. Example of a moderate-fragile geoecological landscape in the municipality of Sandovalina. A) Field photo; B) Location of the area at the UGRHI-22; C) Aerial view of the site from aerial photography (available from EMPLASA, 2011). 
sível observar, à esquerda, um corredor ecológico interligado com o fragmento Tucano, ao fundo, fragmento esse pertencente à Estação Ecológica Mico-Leão-Preto, enquanto ao seu lado, à direita, encontra-se uma extensa monocultura de cana-de-açúcar.

Estado Geoecológico Homeostático: as unidades Homeostáticas correspondem aos setores onde existe uma pedogênese ativa, com solos espessos de caráter latossólico em relevo de colinas baixas, pouco dissecadas e com baixa densidade de drenagem. Essas unidades são recobertas por vegetações nativas de porte médio a alto, que oferecem proteção ao solo e aos corpos d'água locais. Recomenda-se que permaneçam inalteradas, uma vez que abrigam e regem diversas formas de vida, de fauna e flora. A ocupação humana, quando próxima dessas áreas, deve poupar ao máximo os recursos naturais, com baixa ou nula intervenção. Entretanto, assim como na unidade anterior (moderado-homeostática), essas unidades, apesar de serem naturalmente homeostáticas (tendo em vista as características do meio físico que apresentam), encontram-se atualmente próximas a expressivos cultivos de cana-de-açúcar, o que pode comprometer a qualidade do ambiente local e regional, danificando ou degradando os recursos naturais encontrados às suas adjacências (Fig. 7). Na figura 7C observa-se, no primeiro plano, o Parque Estadual do Morro do Diabo, e no segundo plano, o Assentamento Ribeirão Bonito.

\section{Discussão dos resultados}

A síntese dos componentes da paisagem, representada pelo mapa geoecológico, possibilita delinear, regionalmente, áreas susceptíveis a determinados impactos negativos relacionados às atividades antrópicas em superfície. Entende-se que essa visão macro auxilia o planejamento e a gestão da Unidade de Gerenciamento avaliada, buscando evidenciar áreas fisicamente frágeis no que diz respeito aos processos naturais da paisagem. Para isso, o emprego de metodologias apoiadas no estudo sistêmico desses componentes demonstra ser uma alternativa viável e rápida para a construção de tal síntese.

No caso do presente trabalho, convém destacar a proximidade com a metodologia apresentada

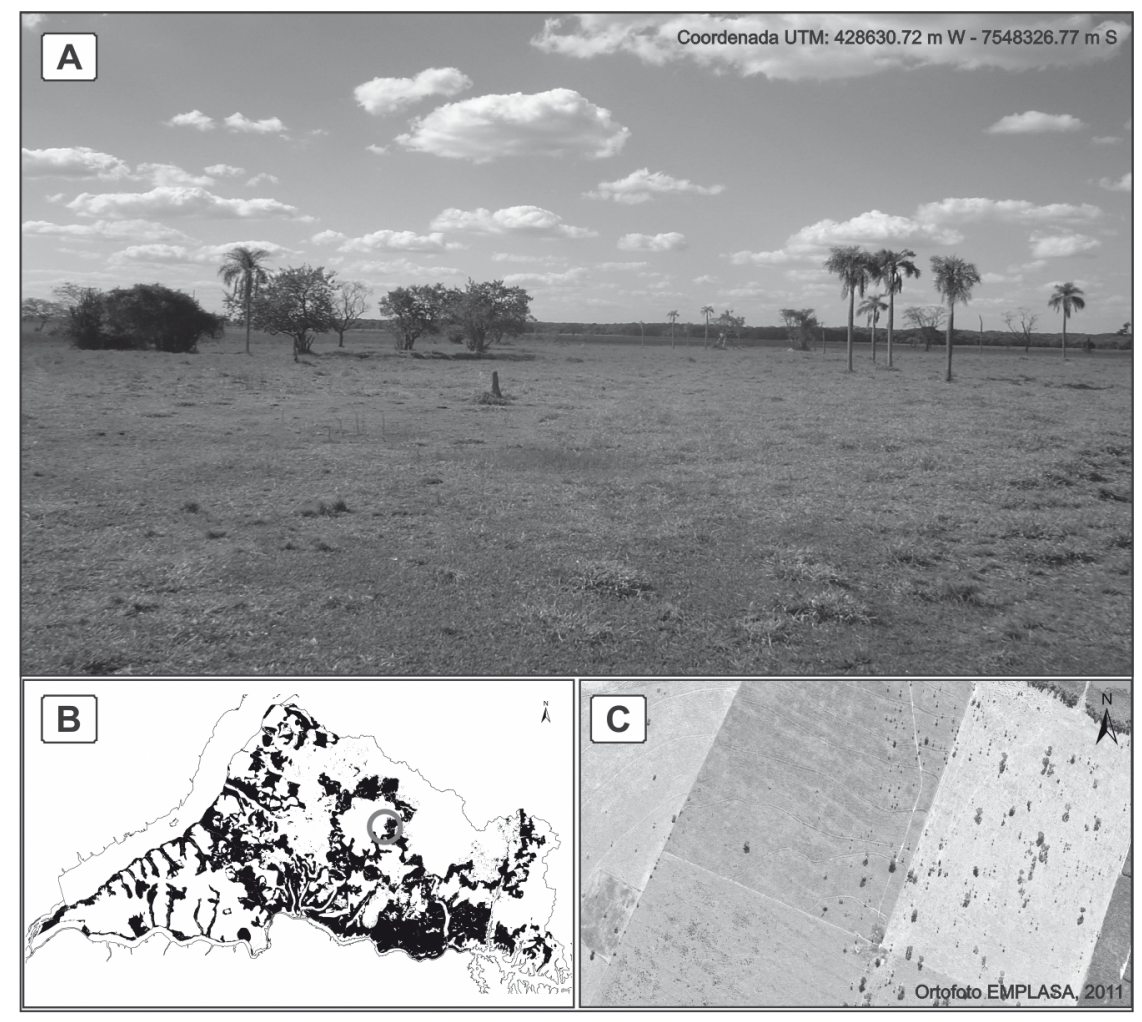

Figura 5. Exemplo de paisagem em estado geoecológico intermediário no município de Presidente Bernardes. A) Foto em campo; B) Localização da área na UGRHI-22; C) Visão aérea do local a partir de fotografia aérea (disponibilizada pela EMPLASA, 2011).

Figure 5. Example of an intermediate geoecological landscape in the municipality of Presidente Bernardes. A) Field photo; B) Location of the area at the UGRHI-22; C) Aerial view of the site from aerial photography (available from EMPLASA, 2011). 
por Crepani et al. (2001), que aplicaram a ponderação de valores por meio da álgebra de mapas para definir áreas susceptíveis à erosão. De maneira semelhante ao método aqui utilizado, os autores utilizaram os princípios definidos por Tricart (1977) referentes ao balanço pedogênese/morfogênese. A diferença repousa no enfoque tratado pela Geoecologia, que se preocupa em diagnosticar a área e estabelecer relações entre as interações da natureza e do homem.

As classes geoecológicas estabelecidas apoiam-se no conceito dos processos de degradação de geossistemas apresentado por Rodriguez et al. (2013). Neste contexto, os autores demonstram que, quando determinado ambiente está sob baixa interação antrópica, o mesmo apresenta um estado homeostático, e, conforme ocorre o aumento ou incremento dessa interação, o ambiente passa para um estado fragilizado. Os graus mínimo e máximo, assim como a separação desses valores em cinco classes a partir de seu desvio padrão, distribuem-se entre os estados homeostático, moderado-homeostático, intermediário (ou Integrade, cujo termo baseia-se no modelo proposto por Tricart, 1977), moderado-fragilizado e fragilizado.

Nos setores classificados como de estado geoecológico homeostático, a cobertura de vegetação nativa é responsável por contribuir diretamente com a delineação das áreas. O Parque Estadual do Morro do Diabo, localizado no município de Teodoro Sampaio, é a maior área em estado homeostático na UGRHI-22. Seus arredores, por sua vez, encontram-se descampados e, portanto, com maiores graus de fragilidade do que o Parque em si. Amaral \& Ross (2009) evidenciam essa situação de maneira semelhante ao elaborarem uma carta da área destacando os setores em unidades ecodinâmicas com instabilidade potencial (estáveis) e com instabilidade emergente (instáveis). 0 método empregado neste estudo baseia-se, sobretudo, na análise integrada dos dados, representando a combinação dinâmica dos elementos físicos, biológicos e antrópicos que compõem a paisagem. $\mathrm{Na}$ carta produzida, Amaral \& Ross (2009) demonstram a importância da cobertura vegetal do Parque por favorecer os processos de pedogênese,

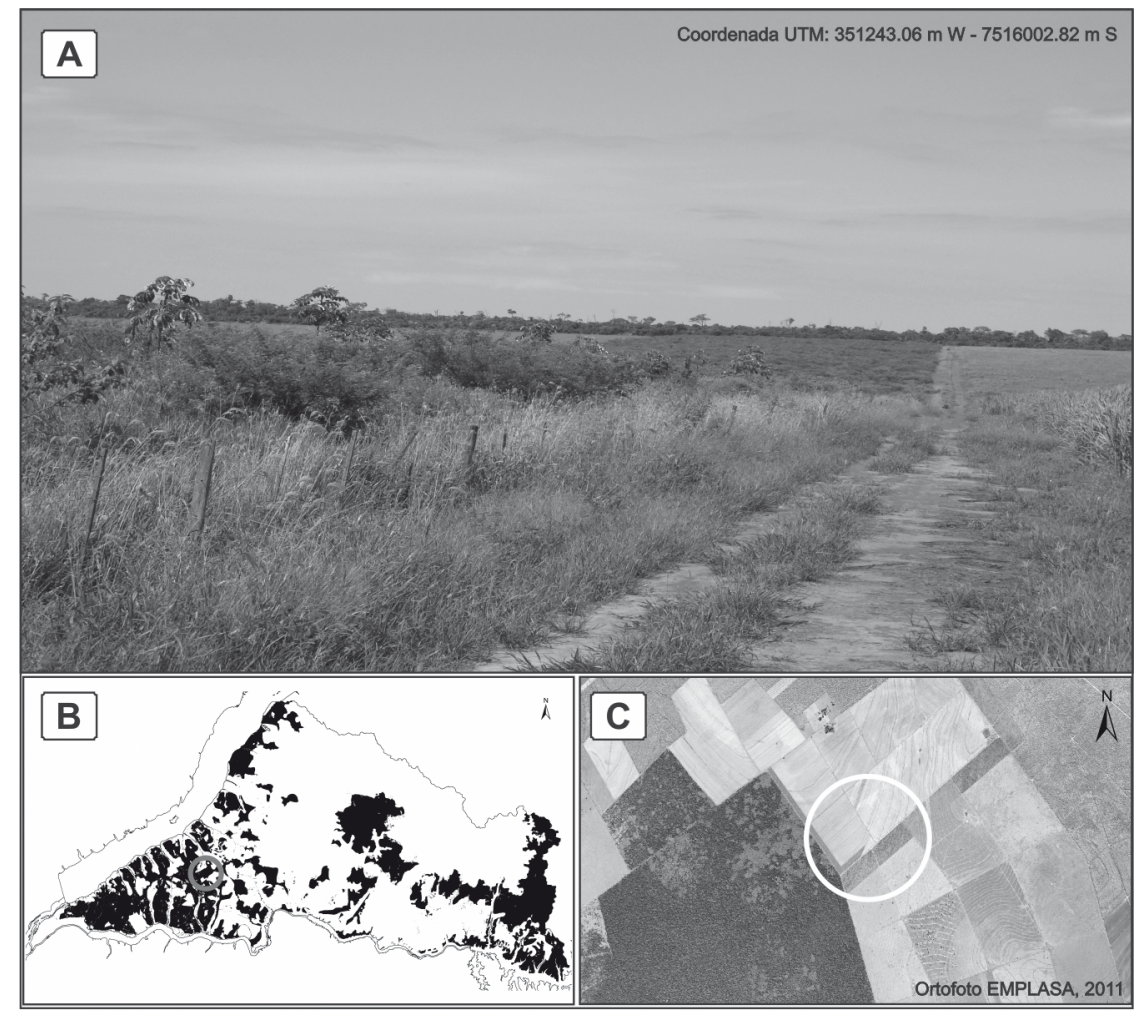

Figura 6. Exemplo de paisagem em estado geoecológico moderado-homeostático no município de Teodoro Sampaio; A) Foto em campo; B) Localização da área na UGRHI-22. C) Visão aérea do local a partir de fotografia aérea (disponibilizada pela EMPLASA, 2011).

Figure 6. Example of a moderate-homeostatic geoecological state in the municipality of Teodoro Sampaio. A) Field photo; B) Location of the area at the UGRHI-22; C) Aerial view of the site from aerial photography (available from EMPLASA, 2011). 
assim como atribuem maiores graus de fragilidade aos cursos d'água presentes na região.

Sobre os setores com estado geoecológico moderado-homeostático, as características do modelado favorecem o uso da terra para culturas mecanizadas, como por exemplo a cana-de-açúcar que, ao longo das últimas décadas, tem ocupado amplamente as regiões mais aplainadas do Pontal (Thomaz et al., 2012). Não obstante, ainda que essas áreas apresentem baixos graus de fragilidade, a ocupação da monocultura pode comprometer a estabilidade da biota local, além de, quando executada de maneira errônea, reduzir a qualidade do solo e dos recursos hídricos presentes, o que promove um novo ciclo de degradação ambiental e paisagístico da UGRHI-22. Um setor de destaque destas áreas coincide com o centro da UGRHI-22, em uma região definida como Planalto das Lagoas (Stein, 1999) ou Depressão de Presidente Bernardes (Paula e Silva et al., 2003). Etchebehere et al. (2008) apontam que, sobre esta localidade, a movimentação de blocos rochosos permitiu a singularidade do relevo, e o aplainamento desse setor proporciona características geofísicas únicas para a área, uma vez que favorece a formação de solos mais profundos e trabalhados. A presença exacerbada das lagoas, por sua vez, consiste em um importante recurso hídrico para a captação e uso agrícola, o que atrai o desenvolvimento da monocultura citada.

As áreas de estado geoecológico intermediário pouco destoam, no que diz respeito ao uso da terra, das áreas de estado moderado-homeostático (conforme destacado no Quadro 6). No entanto, devido ao desmatamento da cobertura arbórea nativa para a abertura de atividades agropecuárias, a consequente redução da infiltração de águas pluviais sobre terrenos arenosos rebaixou os níveis dos freáticos encontrados, o que, por sua vez, causa a desperinização dos corpos d'água superficiais. Essa condição torna-se evidente quando comparados mapeamentos envolvendo a região da rede de drenagem em décadas anteriores (Leite, 1998) com os dados atuais. Na região do Pontal do Paranapanema, nos municípios de Rosana, Euclides da Cunha Paulista e Teodoro Sampaio, os corpos d'água foram desperenizados com maior intensidade ao longo das últimas décadas sobre super-

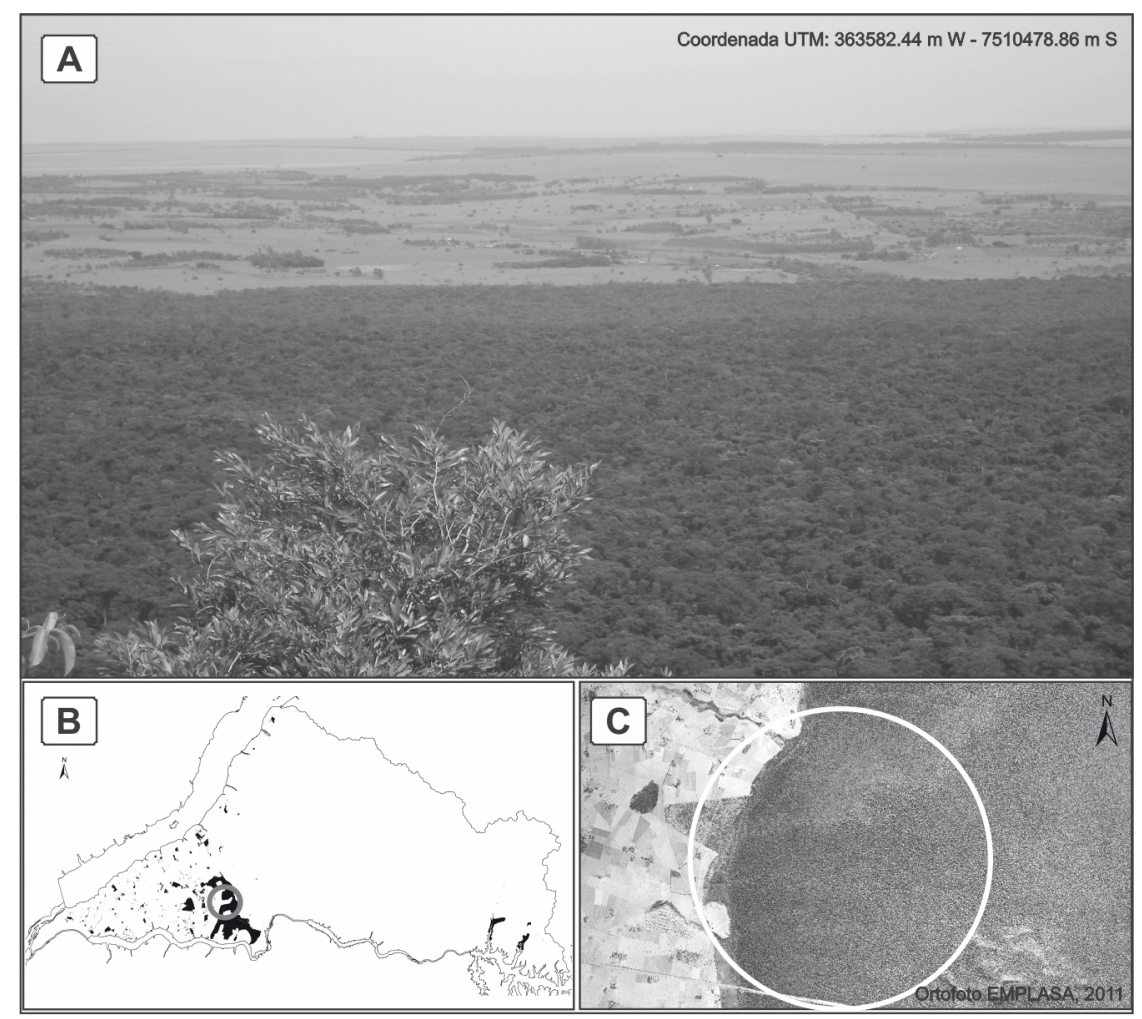

Figura 7. Exemplo da paisagem em estado geoecológico homeostático no município de Teodoro Sampaio. A) Foto em campo; B) Localização da área na UGRHI-22; C) Visão aérea do local a partir de fotografia aérea (disponibilizada pela EMPLASA, 2011). Figure 7. Example of the landscape in a homeostatic geoecological state in the municipality of Teodoro Sampaio. A) Field photo; B) Location of the area at the UGRHI-22; C) Aerial view of the site from aerial photography (available from EMPLASA, 2011). 
fícies mais permeáveis originárias da Formação Caiuá (estado geoecológico intermediário e moderado-fragilizado).

No setor norte da UGRHI-22, as características geoecológicas são governadas pela prevalência da morfogênese sobre a pedogênese, uma vez que o relevo acidentado, em conjunto com a baixa cobertura vegetal natural, proporciona elevados índices de fragilidade. Estes setores são definidos por estados geoecológicos moderado-fragilizado e fragilizado. 0 local, ainda, coincide com a porção territorial abrangida pela bacia hidrográfica do rio Santo Anastácio, cuja área exibe o maior número de processos erosivos do estado de São Paulo (IPT, 1994). Em municípios como Presidente Prudente e Marabá Paulista, onde ocorrem solos da Formação Adamantina $\mathrm{Ka}_{\mathrm{v}}$ e $\mathrm{Ka}_{\mathrm{v}}$ e Santo Anastácio, os processos erosivos são de grandes dimensões. Ambos os municípios se encontram sobre altos Estruturais e altos Topográficos, evidenciados em Nunes (2002), acompanhando os setores de estado geoecológico moderado-fragilizado e fragilizado.

Nas regiões consideradas fragilizadas são, ainda, encontrados os rios com maiores quantidades de sedimentos ou processos de assoreamento, como nos afluentes do ribeirão Claro (em Presidente Venceslau) e nos tributários do rio Santo Anastácio, como o Areia Dourada (em Marabá Paulista). Isso se deve à intensidade com que os processos erosivos ocorrem nesses setores. Zanatta et al. (2015) evidenciam essas informações ao elaborarem uma carta contendo as unidades paisagísticas da bacia hidrográfica do ribeirão Areia Dourada. 0 método apresentado pelos autores pauta-se na intensidade dos processos erosivos proporcionados pela declividade e energia do relevo em conjunto com o uso da terra local, e confirmam a necessidade de práticas de recuperação dessas áreas, conforme apontado no presente trabalho (Quadro 6).

De maneira geral as principais áreas urbanas da UGRHI-22 concentram-se sobre o divisor de águas do rio Santo Anastácio com o rio do Peixe, coincidindo com as áreas em estados geoecológicos intermediário, moderado-fragilizado e fragilizado. A paisagem denota os maiores índices de degradação do meio físico em razão da intensificação de processos erosivos diversos e do meio biótico, uma vez que essas áreas são caracterizadas pela ausência de cobertura vegetal. Esta degradação, consequentemente, torna-se prejudicial para a qualidade do recurso hídrico disponível para a população. Dibieso (2013) elaborou uma carta contendo unidades de paisagem para os mananciais do rio Santo Anastácio. 0 método empregado na elaboração da carta baseia-se nos princípios de
Tricart (1977) e aponta a problemática envolvendo os solos da Formação Adamantina $\left(\mathrm{Ka}_{\mathrm{v}}\right.$ e $\left.\mathrm{Ka}_{\mathrm{IV}}\right)$ e as implicações para os recursos hídricos existentes na área, que se encontram sujeitos aos impactos provenientes da ocupação proporcionada pela expansão da malha urbana de Presidente Prudente.

A degradação é intensificada por atividades altamente impactantes, como as industriais, e pela presença de depósitos de resíduos sólidos, que resultam na degradação visual, social e econômica perceptíveis na paisagem. Oliveira (2015), ao trabalhar com a escolha de áreas para aterros sanitários de resíduos sólidos no município de Anhumas, apoia-se na teoria da paisagem e da Geoecologia para determinar unidades de paisagem denotando a fragilidade natural do município. 0 método empregado pelo autor, de maneira semelhante ao resultado apresentado no mapa geoecológico (Fig. 2), demonstra que o norte do município, situado sobre a formação Adamantina $\left(\mathrm{Ka}_{\mathrm{v}}\right)$ oferece pouca ou nula capacidade geotécnica para abrigar um empreendimento altamente impactante, coincidindo com o estado geoecológico moderado-fragilizado e fragilizado atribuído a este setor.

Sobre as áreas mais frágeis, as características do relevo e do solo, aliadas ao uso da terra e à baixa cobertura vegetal nativa, destaca-se o predomínio da morfogênese sobre a pedogênese, com acentuada transformação no modelado, onde o escoamento superficial e as oscilações no nível dos lençóis freáticos têm desencadeado a formação de ravinas e boçorocas. Aqui, ocorre uma oposição entre as áreas onde constam os sistemas naturais parcialmente preservados e/ou conservados e as áreas onde prevalecem elementos dos sistemas antrópicos. Nas áreas dos sistemas naturais, de baixa ocorrência no território em estudo, há a urgente necessidade de restauração de seus atributos naturais para a sustentabilidade dos ecossistemas, com a restauração da cobertura vegetal nativa, através da implantação de matas ciliares, reservas legais e corredores ecológicos.

Na UGRHI-22, a captação de água para uso agrícola e pecuário advém principalmente dos freáticos, ou corpos d'água aflorantes, e, portanto, constituem-se como importantes fontes do recurso hídrico regional para as comunidades, urbana e rural, localizadas na região. Nesse sentido, o que se deve buscar é o bom emprego da estrutura espacial, considerando a otimização de usos dos sistemas ambientais, almejando o maior grau de indicadores de diversidade (bio, geo e sociodiversidade) no Pontal. As áreas ainda não protegidas por tal mecanismo legal, como as áreas de entorno dos rios, nascentes e encostas florestadas, apresen- 
tam forte tendência a transformações ambientais decorrentes da ocupação desordenada, que gera o esgotamento dos recursos naturais, desequilibrando os fluxos de matéria, energia e informação no geossistema.

\section{Conclusões}

Este trabalho propôs a elaboração de um mapa temático de síntese (estado geoecológico) dos componentes naturais de uma das paisagens mais degradadas de todo o estado de São Paulo, a bacia hidrográfica do Pontal do Paranapanema (ou UGRHI-22). Os resultados obtidos na elaboração deste estudo demonstram que, no Pontal do Paranapanema, os graus de fragilidade de suas unidades geoecológicas acusam baixa capacidade de resiliência. 0 uso exacerbado das práticas produtivas do espaço geográfico, acima de sua capacidade de suporte, tem provocado uma degradação sem precedentes desde o início do século XX, princípio da ocupação e devastação regional.

As características dos sistemas ambientais encontrados neste território, relacionadas a seus componentes naturais (ar, água, rochas e estrutura geológica, solos, vegetação e clima) e com o nível de diferenciação de suas unidades, proporcionam o quadro de fragilidades sintetizado na forma de mapa geoecológico regional. Assim, evidencia-se que a distinção da UGRHI-22 em unidades de paisagem proporciona uma melhor compreensão da organização do meio físico.

0 diagnóstico geoecológico representa um passo importante para determinar as consequências de determinadas atividades humanas na superfície, principalmente aquelas que exigem cuidados específicos, justamente por permitir avaliar as características paisagísticas regionais. É importante considerar a diversidade e a diferença entre unidades ambientais de distintas dimensões encontradas no Pontal do Paranapanema, especialmente porque as mesmas se caracterizam por diferentes graus de estabilidade em relação aos impactos antrópicos, apresentando capacidade distinta de resiliência, assim como diferentes aptidões de conservação e restituição de seus serviços ambientais à sociedade.

No Pontal do Paranapanema, a fragilidade do geossistema natural de baixa resiliência e estabilidade gera um geossistema econômico de baixa sustentabilidade que, por sua vez, debilita o geossistema social, formando um círculo vicioso que só será rompido com um planejamento adequado, utilizando suas unidades geoecológicas de acordo com sua capacidade de suporte e restaurando os ecossistemas regionais. A maneira como a ocupação ocorre nesses espaços geográficos ocasiona impactos como a contaminação do ar, dos solos, dos níveis freáticos pelos efluentes domésticos ou industriais, pelas fossas assépticas, o acúmulo de lixo, a poluição das águas e também a poluição visual, prejudicando a qualidade de vida da população. Recomenda-se que futuros trabalhos tratem dos aspectos locais da UGRHI-22, de modo a se obter uma melhor compreensão da dinâmica natural atuante.

A partir de um levantamento mais detalhado das características da bacia, além do reconhecimento de suas potencialidades ou fragilidades, será possível identificar, com maior precisão, os problemas advindos das atividades antrópicas desenvolvidas na região hidrográfica do Pontal do Paranapanema. Sugere-se, ainda, a elaboração de estudos que contemplem a ordenação do espaço geográfico, o que exige a complementação de demais levantamentos voltados para as características sociais, econômicas, sanitárias, biológicas e jurídicas. Tais informações, atreladas a um planejamento ambiental sistêmico e embasado na teoria da paisagem permitirá a compreensão ambiental e a ocupação sustentável de toda essa região do estado de São Paulo.

Agradecimentos - Os autores agradecem à Coordenação de Aperfeiçoamento de Pessoal de Nível Superior (CAPES) pela bolsa concedida e financiamento da pesquisa de Mestrado, e ao Núcleo de Estudos Ambientais e Geoprocessamento (NEAGEO) pelo suporte oferecido.

\section{Referências}

Abreu, A.A. 1983. A teoria geomorfológica e sua edificação: análise crítica. Revista do Instituto Geológico, 4 (1/2): 5-23.

AGG. Association for Geoecology in Germany. 2005. Geoökologie studieren. Disponível em: <http://www. geooekologie.de/download/studium_2005.pdf $>$. Acesso em: 20 jul. 2015.

Almeida, M.A., Dantas, A.S.L., Fernandes, L.A., Sakate, M.T., Gimenez, A.F., Teixeira, A.L., Bistrichi, C.A. \& Almeida, F.F.M. 1981. Considerações sobre a estratigrafia do Grupo Bauru na região do pontal do Paranapanema no Estado de São Paulo. In: ATAS SIMPÓSIO REGIONAL DE GEOLOGIA, 3, SBG - SP, Atas... Curitiba. v. 2, p. 77-89.

Almeida, M.A., Stein, D.P., Melo, M.S., Bistrichi, C.A., Ponçano, W.L., Hasui, Y. \& Almeida, F.F.M. 1980. Geologia do Oeste Paulista e Áreas Fronteiriças dos Estados de Mato Grosso do Sul e Paraná. In: CONGRESSO BRASILEIRO DE GEOLOGIA, XXXI, Anais... Balneário de Camboriú, Santa Catarina, v. 5, p. 2799-2812.

Amaral, R. \& Ross, J.L.S. 2009. As Unidades Ecodinâmicas na Análise da Fragilidade Ambiental do Parque 
Estadual do Morro do Diabo e Entorno, Teodoro Sampaio/SP. GEOUSP - Espaço e Tempo, 26: 59-78.

Boin, M.N. 2000. Chuvas e Erosões no Oeste Paulista: Uma Análise Climatológica Aplicada. Rio Claro, 264p. Tese de Doutorado, Programa de Pós-graduação em Geociências e Meio Ambiente, Instituto de Geociências e Ciências Exatas, Universidade Estadual Paulista.

CPTI. Cooperativa de Serviços e Pesquisas Tecnológicas e Industriais. 1999. Diagnóstico da situação dos recursos hídricos da UGRHI - 22: Pontal do Paranapanema: Relatório Zero. São Paulo: CPTI, CD-ROM.

Crepani, E., Medeiros, J.S. de, Hernandez Filho, P., Florenzano, T G., Duarte, V. \& Barbosa, C.C.F. 2001. Sensoriamento remoto e geoprocessamento aplicados ao zoneamento ecológico-econômico e ao ordenamento territorial. Disponível em: <http://www.dsr.inpe. br/laf/sap/artigos/CrepaneEtAl.pdf>. Acesso em: 7 maio. 2015.

Dibieso, E.P. 2013. Planejamento ambiental e gestão dos recursos hídricos: estudo aplicado à bacia hidrográfica do manancial do alto curso do Rio Santo Anastácio - São Paulo/Brasil. Presidente Prudente, 283p. Tese de Doutorado, Programa de Pós-graduação em Geografia, Universidade Estadual Paulista.

Drew, D. 1986. Processos interativos homem meio ambiente. Trad. de João Alves dos Santos. São Paulo: Difel, 206p.

EMBRAPA. Empresa Brasileira de Pesquisa Agropecuária. 1999. Mapa pedológico do Estado de São Paulo. Campinas, Instituto Agronômico, Rio de Janeiro, EMBRAPA Solos, 1 v., escala 1:1.000.000.

EMPLASA. Empresa Paulista de Planejamento Metropolitano. 2011. Produtos cartográficos: projeto mapeia São Paulo - Ortofotos digitais. Disponível em: <http://www.emplasa.sp.gov.br/emplasa/EmplasaEleicao/ortofotos.asp>. Acesso em: 17 jul. 2015.

Etchebehere, M.L.C., Morales, N., Stevaux, J.C. \& Santoni, G.C. 2008. Feições de liquefação no vale do rio Santo Anastácio (SP): indicações de atividade sísmica quaternária? Revista UnG, Geociências, 7(1): 64-77.

IBGE. Instituto Brasileiro de Geografia e Estatística. 2012. Manual técnico da vegetação brasileira. 2a. ed., Rio de Janeiro, IBGE, 271p.

IBGE. Instituto Brasileiro de Geografia e Estatística. 2015. Banco de dados georeferenciado sobre recursos naturais. Base cartográfica, em formato vetorial, SHP, na escala 1:250.000. Disponível em: <http:// mapas.ibge.gov.br/bases-e-referenciais/bases-cartograficas>. Acesso em: 21 mai. 2015.

IPT. Instituto de Pesquisas Tecnológicas do Estado de São Paulo. 1981a. Mapa Geomorfológico do estado de São Paulo. São Paulo, Secretaria da Indústria, Comércio, Ciência e Tecnologia, IPT. v. 2, escala: 1:1.000.000.

IPT. Instituto de Pesquisas Tecnológicas do Estado de São Paulo. 1981b. Mapa Geológico do estado de São Paulo. São Paulo, Secretaria da Indústria, Comércio, Ciência e Tecnologia, IPT, v. 1, escala 1:500.000.

IPT. Instituto de Pesquisas Tecnológicas do Estado de São Paulo. 1994. Bases técnicas para a recuperação da bacia do rio Santo Anastácio, 3a fase. São Paulo:
IPT, 94p. (Relatório 32.257)

Landim, P.M.B., Souza Filho, E.E. \& Neto, A.F.S. 1984. O estudo morfoestrutural pela análise de superfícies de tendência. Geociências, 3(1): 77-89.

Leite, J.F. 1998. A ocupação do Pontal do Paranapanema. São Paulo: HUCITEC. 89p.

Melo, K.C. 2012. Geoecologia Da Paisagem Do Município De Ubatuba - SP. Eixo Temático: Geografia Física e Educação Ambiental: Desafios Contemporâneos. Revista GEONORTE, 3(4): 997-1009.

Nunes, J.O.R. 2002. Uma contribuição metodológica ao estudo da dinâmica da paisagem aplicada a escolha de áreas para construção de aterro sanitário em Presidente Prudente. Presidente Prudente, 209p. Tese de Doutorado, Programa de Pós-graduação em Geografia, Faculdade de Ciência e Tecnologia, Universidade Estadual Paulista.

Oliveira, R.C. 2015. Escolha de Área para Aterro Sanitário em Meios Porosos: o Caso do Município de Anhumas (SP). Presidente Prudente, 186p. Dissertação de Mestrado, Programa de Pós-graduação em Meio Ambiente e Desenvolvimento Regional, Universidade do Oeste Paulista.

Oliveira, R.C., Osco, L.P. \& Boin, M.N. 2015. A geologia do município de Anhumas (SP) e seus reflexos nos recursos hídricos. Colloquium Humanarum, 12(1): 14-20.

Paula e Silva, F., Chang, H.K. \& Caetano-Chang, M.R. 2003. Perfis de referência do grupo Bauru (K) no estado de São Paulo. Geociências, 22 (n. esp.): 21-32.

Rodriguez, J.M.M., Silva, E.V. \& Cavalcanti, A.P.B. 2013. Geoecologia das Paisagens: Uma Visão Geossistêmica da Análise Ambiental. Fortaleza: Educações UFC. $222 \mathrm{p}$.

Ross, J.L.S. \& Moroz, I. C. 1997. Mapa Geomorfológico do Estado de São Paulo. São Paulo: Laboratório de Geomorfologia. Departamento de Geografia FFLCH-USP/Laboratório de Cartografia Geotécnica - Geologia Aplicada - IPT/FAPESP, v. 1, escala 1:500.000.

Santoro, J. \& Massoli, M. 1985. Mapa de contorno estrutural do topo do basalto subjacente ao Grupo Bauru no estado de São Paulo. Revista do Instituto Geológico, 6(1/2): 39-44.

Santos, L.F., Guedes, I.C. \& Etchebehere, M.L. de C. 2011. Análise Neotectônica do Pontal do Paranapanema (SP) Mediante Aplicação de Parâmetros Fluviomorfométricos. Geociências, 30(4): 491-507.

Silva, E.V. 2012. Geografia Física, Geoecologia da Paisagem e Educação Ambiental Aplicada: Interações Interdisciplinares na Gestão Territorial. Eixo Temático: Geografia Física e Educação Ambiental: Desafios Contemporâneos. Revista GEONORTE, 4(4): 175183.

Soares, P.C., Landim, P.M.B., Fulfaro, V.J. \& Neto, A.F.S. 1980. Ensaios de caracterização estratigráfica do cretáceo no Estado de São Paulo: Grupo Bauru. Revista Brasileira de Geociências, 10(3): 170-185.

Sotchava, V.B. 1977. 0 estudo de geossistemas. Caderno Métodos em Questão, 16: 1-52.

Stein, D.P. 1999. Avaliação da degradação do meio físico - Bacia do rio Santo Anastácio, oeste paulista. Rio 
Claro, 197p. Tese de Doutorado, Programa de Pós-graduação em Geociências, Instituto de Geociências e Ciências Exatas, Universidade Estadual Paulista.

Thomaz Jr., A., Guimarâes, R.B., Leal, A.C. \& Luchiari, A. 2012. Conflitos territoriais, relações de trabalho e saúde ambiental no agrohidronegócio canavieiro no Pontal do Paranapanema (SP). In: COLOQUIO INTERNATIONAL DE GEOCRÍTICA, XXII, Las indepedencias y construción de estados nacionales: poder, territoralización y sociealización, siglos XIX-XX. Bogotá. $13 p$.

Manuscrito 594

Editores: Carla E. Barros \& Paulo A. Souza
Tricart, J.A. 1977. Ecodinâmica. Rio de Janeiro: IBGE-SUPREN, Recursos Naturais e Meio Ambiente, 91p.

Zanatta, F.A.S., Lupinacci, C.M. \& Boin, M.N. 2015. 0 uso da terra e alterações do relevo na alta bacia do ribeirão Areia Dourada, Marabá Paulista (SP): um estudo a partir de princípios da antropogeomorfologia. Revista Brasileira de Geomorfologia. 16(1): 03-17.

Zonneveld, I.S. 1989. The land unit - A fundamental concept in landscape ecology, and its applications. Landscape Ecology, 3(2): 67-86. 
